\title{
Winter growth and tidal variability of the sub-ice platelet layer observed with electromagnetic induction soundings
}

Gemma M. Brett ${ }^{1}$, Greg. H. Leonard ${ }^{2}$, Wolfgang Rack ${ }^{1}$, Christian Haas ${ }^{3,4,5,6}$, Patricia J. Langhorne ${ }^{7}$, and Anne Irvin ${ }^{4,8}$

5

${ }^{1}$ Gateway Antarctica, University of Canterbury, Christchurch, New Zealand

${ }^{2}$ School of Surveying, University of Otago, Dunedin, New Zealand

${ }^{3}$ Department of Earth and Atmospheric Science, University of Alberta, Edmonton, Canada

${ }^{4}$ Department of Earth and Space Science and Engineering, York University, Toronto, Canada

$10{ }^{5}$ Alfred Wegener Institute for Polar and Marine Research, Bremerhaven, Germany

${ }^{6}$ Department of Environmental Physics, University of Bremen, Bremen, Germany

${ }^{7}$ Department of Physics, University of Otago, Dunedin, New Zealand

${ }^{8}$ Department of Geography, Memorial University of Newfoundland, St. John's, Canada

Correspondence to: Gemma M. Brett, (gemma.brett@canterbury.ac.nz)

Abstract. Here, we present the first electromagnetic induction time-series measurements of ice shelf-influenced fast ice and sub-ice platelet layer thickness over winter and in late spring in McMurdo Sound. Significant increases in sub-ice platelet layer thickness ( 0.5-1 m) co-occurred with strong southerly wind events and satellite-observed polynya activity suggesting winddriven surface circulation of supercooled Ice Shelf Water outflow from the McMurdo-Ross ice shelf cavity. Temporal variability observed in sub-ice platelet layer thickness on diurnal timescales correlated with tidally-induced current patterns previously observed in McMurdo Sound. The thickness of the sub-ice platelet layer increased on spring and neap ebb tides corresponding with northward currents circulating out from the ice shelf cavity. The late spring spatial distributions of firstyear and second-year fast ice and sub-ice platelet layer thickness in McMurdo Sound were assessed with drill hole and electromagnetic induction surveys and were comparable to a previous four-year dataset. We resolved second-year fast ice thicknesses of $4 \mathrm{~m}$ with a substantial sub-ice platelet layer beneath of up to $11 \mathrm{~m}$ using electromagnetic induction techniques suggesting that the longer temporal persistence of the two-year-old fast ice allowed a substantially thicker sub-ice platelet layer to form. The variability observed in the sub-ice platelet layer indicates that a combination of the tides, wind-driven polynya activity and the presence of multi-year ice influences the circulation of Ice Shelf Water in the upper surface ocean and consequently sub-ice platelet layer formation over a range of timescales.

\section{Introduction}

In the western Ross Sea, sea ice production in coastal polynyas forms High Salinity Shelf Water (HSSW) (Ohshima et al., 2016) which circulates into the conjoined McMurdo-Ross ice shelf cavity and drives basal melting at depth in the grounding zone (Jacobs et al., 1992). The meltwater has a potential temperature below the surface freezing point (Jacobs et al., 1985) and is 
https://doi.org/10.5194/tc-2021-61

Preprint. Discussion started: 17 May 2021

(c) Author(s) 2021. CC BY 4.0 License.

(c) (i)

classified as Ice Shelf Water (ISW). ISW is relatively fresh and buoyant, and can rise along the ice shelf base from deep source regions in the cavity (Macayeal, 1984). As ISW rises adiabatically and the pressure decreases, it can become supercooled (Foldvik and Kvinge, 1974; Jenkins and Bombosch, 1995) promoting frazil ice formation (Holland and Feltham, 2005; Robinson et al., 2014). Frazil ice can grow into larger platelet ice crystals with continued bathing in supercooled ISW (Smith et al., 2012).

40 Supercooled ISW with a suspension of frazil and platelet ice reaches the upper surface ocean in McMurdo Sound (Hughes et al., 2014; Lewis and Perkin, 1985; Robinson et al., 2014). Ice crystals are deposited beneath fast ice in the region where they can continue to grow in-situ (Langhorne et al., 2015; Leonard et al., 2011; Smith et al., 2001). As the sea ice grows, platelet ice crystals can freeze into the base forming consolidated platelet ice (Smith et al., 2012; Smith et al., 2001). An unconsolidated mass of platelet ice crystals called a sub-ice platelet layer (SIPL) can form beneath the consolidated sea ice when the freezing rate is exceeded by the rate of ice crystal deposition from the water column (Dempsey et al., 2010; Hoppmann et al., 2015a; Gough et al., 2012). The thickness and volume of ice shelf-influenced fast ice and the SIPL in McMurdo Sound are the direct manifestation of supercooled ISW outflow (Langhorne et al., 2015), and the regional atmospheric and oceanographic processes driving polynya activity, HSSW and ISW formation (Brett et al., 2020b).

The spatial distributions of ice shelf-influenced fast ice and the SIPL have been well observed in McMurdo Sound using a variety of techniques including ice coring (Dempsey et al., 2010; Gough et al., 2012), drill hole measurements (Brett et al., 2020b; Price et al., 2014), electromagnetic induction (EM) surveying (Brett et al., 2020b; Haas et al., 2020; Rack et al., 2013) and satellite altimetry (Brett et al., 2020a; Price et al., 2015; Price et al., 2013). The development of a supercooled ISW plume over winter, and the effects on fast ice formation in McMurdo Sound have been investigated in previous studies (Hunt et al., 2003; Leonard et al., 2011; Leonard et al., 2006; Mahoney et al., 2011; Gough et al., 2012). However, most observations in McMurdo Sound were made at the end of the sea ice growth season in late spring and captured a fully developed fast ice cover and SIPL.

The evolution of ice shelf-influenced fast ice and SIPL over winter have not been frequently observed nor has variability in the SIPL over diurnal timescales (Hoppmann et al., 2020). Drill hole measurements in Atka Bay (Queen Maud Land) captured SIPL and fast ice growth over winter (Arndt et al., 2020; Hoppmann et al., 2015a; Hoppmann et al., 2015b). However, these point measurements were made every 2-5 weeks and no diurnal variability in the SIPL could be observed. Brett et al. (2020b) applied

60 an EM technique to obtain high resolution measurements of fast ice and SIPL thickness in McMurdo Sound in late spring. They detected significant increases in SIPL thickness occurring over days and weeks in repeat EM surveys near Hut Point Peninsula (refer to Fig. 1b). This is an important region for water mass exchange between open ocean in the Ross Sea and the ice shelf cavity (Assmann et al., 2003; Hunt et al., 2003; Leonard et al., 2011; Leonard et al., 2006; Mahoney et al., 2011; Robinson et al., 2010; Stern et al., 2013). Temporal variability in SIPL thickness and distribution is considered to be strongly coupled to variability in the volume of supercooled ISW circulating beneath the fast ice (Langhorne et al., 2015). 
In this study, the growth of ice shelf-influenced fast ice and the SIPL are measured over winter near the McMurdo Ice Shelf (MIS) in the east, and in the following late spring over a spring-neap tidal cycle in the main path of ISW outflow in the west (Fig 1c). For the first time, an EM instrument was deployed over winter in Antarctica which successfully captured time-series measurements of the growth of ice shelf-influenced fast ice and a SIPL beneath. To investigate the possible processes that could influence SIPL formation, variability observed in the SIPL was compared with the occurrence of wind-driven polynya activity over winter, and over shorter diurnal timescales with the oscillation of modelled tides in late spring. In November 2018 , the spatial distributions of fast ice and SIPL in McMurdo Sound were surveyed with EM and drill hole measurements. The methods and results are described in sect. 2 and 3, respectively. In sect. 4, the results are considered with respect to the presence of second-year ice, wind-driven polynya activity and oceanographic circulation in McMurdo Sound.
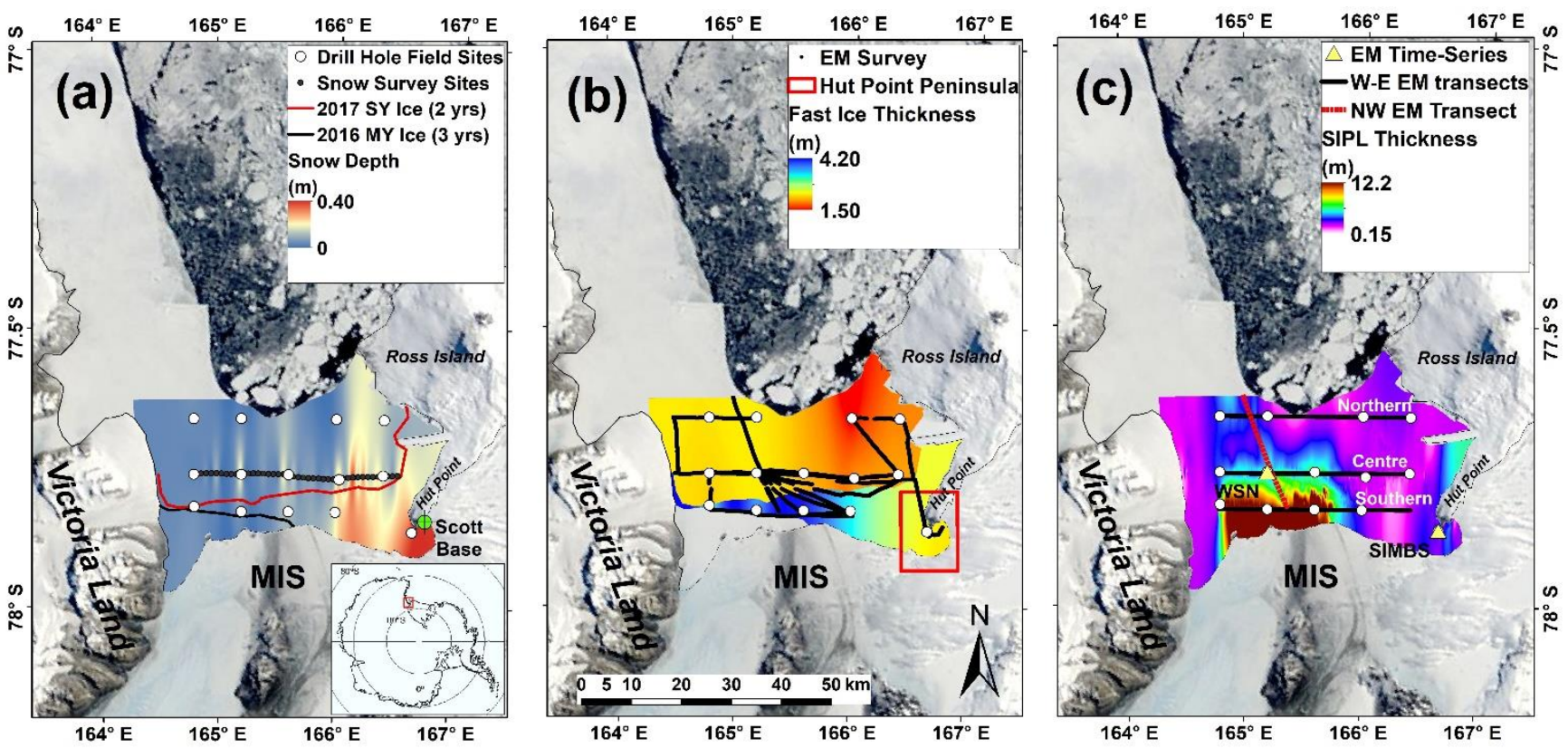

Figure 1. The study area in McMurdo Sound with spatial distributions in November 2018 of a) snow depth, and the thickness of (b) fast ice, and (c) SIPL. (a) Spline interpolated snow depth from measurements made at field sites (white circles) and snow survey sites (black dots) with fast ice sections formed over winter in 2016 (multi-year (MY)) and 2017 (second-year (SY)) delineated with black and red lines, respectively. (b) Drill hole measured 2018 first-year and 2017 second-year fast ice thickness (interpolated separately) with the tracks of all EM surveys (black). (c) EM measured SIPL thickness with the west-east (W-E) and northwest (NW) EM transects to profile fast ice and SIPL thicknesses described in sects. 2.1 and 3.1 and shown in Figs. 3 and 4. The Sea Ice Mass Balance Station (SIMBS) and Western Spring-Neap (WSN) sites are shown (satellite image: NASA MODIS, 19 November 2018). 
https://doi.org/10.5194/tc-2021-61

Preprint. Discussion started: 17 May 2021

(c) Author(s) 2021. CC BY 4.0 License.

(c) (i)

\section{Methods and Data}

The methods and data consist of EM time-series measurements of fast ice and SIPL growth in McMurdo Sound in the east over winter (8 August to 27 October 2018) and in the west in late spring (4-18 November 2018) (refer to sect. 2.2). In November 2018, we assessed the late spring spatial distributions of the thicknesses of fast ice and SIPL (refer to sect. 2.1) with EM and drill hole surveys and re-surveyed the EM transects previously assessed by Brett et al., 2020 in November 2011, 2013, 2016, and 2017. Additionally, a high-resolution gridded EM survey was carried out in the west in November 2018 to assess if the EM instrument could resolve metre-scale features in the SIPL draft (refer to sect. 2.1).

\subsection{Spatial distributions of ice shelf-influenced fast ice and the SIPL}

The spatial distributions of fast ice and SIPL thickness in McMurdo Sound were assessed with ground-based EM surveys and drill hole measurements. The tracks of all EM surveys and drill hole field sites are shown in Fig. 1b. Fourteen field sites distributed over a $\sim 1500 \mathrm{~km}^{2}$ fast ice area in the south of McMurdo Sound were visited between 1 and 19 November 2018. At each field site, fast ice and SIPL thicknesses were measured in 5 drill holes - at the centre and end-points of two $30 \mathrm{~m}$ cross-profiles - using a tape measure with a weighted bar and the resistance method described in Price et al. (2014). Snow depth was measured at field sites (60 measurements at $0.5 \mathrm{~m}$ sample spacing along cross-profiles) and along the Centre transect at $1 \mathrm{~km}$ spacing (60 measurements at $1 \mathrm{~m}$ sample spacing) (Fig. 1a) using a MagnaProbe with integrated GPS.

A single frequency (9.8 kHz: $3.66 \mathrm{~m}$ coil spacing) Geonics Ltd EM31-MK2 instrument was employed for the EM spatial surveys and time-series measurements. For spatial distribution surveys, the instrument was configured according to Brett et al. (2020b) with geo-located EM measurements made at a frequency of $1 \mathrm{~Hz}$ (sample spacing of $\sim 10 \mathrm{~m}$ at typical travel speeds) and for a continuous period of twenty seconds over each of the five drill holes at the 14 field sites. A total distance of $415 \mathrm{~km}$ was surveyed with EM between 1 and 19 November 2018, comprising $270 \mathrm{~km}$ of unique profiles and $145 \mathrm{~km}$ of repeated profiles. The Northern $\left(77.667^{\circ} \mathrm{S}\right)$, Centre $\left(77.767^{\circ} \mathrm{S}\right)$ and Southern $\left(77.833^{\circ} \mathrm{S}\right)$ west-east repeat transects (Fig. 1c) carried out by Brett et al. (2020b)

110 to profile fast ice and SPL thickness in November 2011, 2013, 2016 and 2017 were fully or partially re-surveyed. A northwest transect was carried out along the main circulation pathway of the ISW plume and the thickest mass of SIPL on 6 November 2018 (Fig. 1c).

We investigated the capability of the EM31 instrument to resolve small-scale (metres) features in the SIPL draft. We carried out nine Small-Scale Grid (SSG) EM surveys of fast ice and SIPL thickness on 4, 10, 14 and 18 November 2018 over a $200 \mathrm{~m}$ by 200

$115 \mathrm{~m}$ grid. The south-eastern corner of the SSG was positioned at a drill hole field site on the Centre transect $\left(165.2^{\circ} \mathrm{E}, 77.767^{\circ} \mathrm{S}\right)$ where the Western Spring-Neap EM time-series site was also situated (Fig 1c and sect. 2.2). The SSG surveys were carried out with a range of grid spacings (5, 10 and $50 \mathrm{~m}$ ) and sampling frequencies (1 and $5 \mathrm{~Hz}$ ). We assessed the snow depth distribution on the SSG using a MagnaProbe with measurements made at $5 \mathrm{~m}$ point spacing on gridlines with $50 \mathrm{~m}$ spacing . 
https://doi.org/10.5194/tc-2021-61

Preprint. Discussion started: 17 May 2021

(c) Author(s) 2021. CC BY 4.0 License.

(c) (i)

\subsection{Temporal variability in the SIPL observed with EM time-series measurements}

EM time-series measurements were made at a site in the Hut Point Peninsula region to observe the growth of fast ice and the SIPL over winter in 2018. We referred to this as the Sea Ice Mass Balance Station (SIMBS) site (Fig. 1c). The EM31 was deployed on second-year (SY) fast ice in the Hut Point Peninsula region ( $\left.166.655^{\circ} \mathrm{E}, 77.867^{\circ} \mathrm{S}\right)$ from 8 August to 27 October 2018. The snow layer was removed and the EM31 instrument then placed on the sea ice surface in a weather-proof wooden box. Power was supplied by a 12-volt battery. At 10 min intervals, the EM31 was programmed to power-up for 60 seconds before acquiring data at $1 \mathrm{~Hz}$ for an additional 60 seconds. The data were recorded with ambient air temperature by a Campbell Scientific CR3000 datalogger. The near-real time winter fast ice and SIPL measurements were radio-telemetered to Scott Base (Fig. 1a) where the data were sent to the University of Otago in New Zealand. Drill hole measurements of fast ice and SIPL thicknesses at the SIMBS site were made every 3-4 weeks (4 in total). An additional drill hole measurement was made at the site on 19 November 2018, 23 days after the SIMBS EM time-series ended.

130 The SIMBS EM time-series ran for 80 days (1920 hours) with 1342 hours of high quality data collected. The instrument generally operated well, except when the battery voltage fell below $11 \mathrm{~V}$ or when ambient air temperature measured by the data-logger was below $-30^{\circ} \mathrm{C}$ for prolonged periods of time. The standard deviation of the 60 measurements made every 10 minutes was used to identify low quality in-phase and quadrature data, with values exceeding 50 and 650 parts per million (ppm) (i.e., the ratio of the secondary EM field to the primary EM field generated by the EM31), respectively removed. Generally, the standard deviations of the in-phase and quadrature exceeded those values substantially when air temperature was below $-30^{\circ} \mathrm{C}$.

In the following late spring (November 2018), EM time-series measurements were carried out over a spring-neap tidal cycle in the main path of ISW outflow on the western side of McMurdo Sound. We called this the Western Spring-Neap (WSN) timeseries (Fig. 1c). When the EM31 was not employed for spatial EM surveys, the instrument was deployed on a sledge at a drill hole field site on the Centre transect $\left(165.2^{\circ} \mathrm{E}, 77.767^{\circ} \mathrm{S}\right)$. The WSN site was positioned at the south-eastern corner of the SSG survey. A total of 202 hours of data were collected over five separate time-series intervals of 12-70 hour duration between 4 and 18 November 2018. Given the higher and less variable air temperatures in late spring and our ability to regularly change the EM31 batteries, all data were determined to be of high quality.

\subsection{Forward modelling and inversion of EM measurements}

The processing method from Irvin (2018) and applied by Brett et al. (2020b) was used in this study to simultaneously obtain sea ice and SIPL thicknesses from the in-phase $(I)$ and quadrature $(Q)$ components of single-frequency EM by forward modelling a subsurface comprised of three horizontal conductive layers: 1) total ice thickness (i.e., consolidated sea ice plus snow thickness), 2) a SIPL, and 3) infinitely deep seawater. We forward modelled layers with constant conductivity values of $0 \mathrm{mS} \mathrm{m}^{-1}$ for total ice, $2700 \mathrm{mS} \mathrm{m}^{-1}$ for seawater in McMurdo Sound (Mahoney et al., 2011), and a range of bulk conductivity values for the SIPL $\left(100-1500 \mathrm{mS} \mathrm{m}^{-1}\right)$ for an expected range of thicknesses of total ice $(0.5-6 \mathrm{~m})$ and SIPL $(0-15 \mathrm{~m})$ in $0.01 \mathrm{~m}$ increments. The 
https://doi.org/10.5194/tc-2021-61

Preprint. Discussion started: 17 May 2021

(c) Author(s) 2021. CC BY 4.0 License.

(c) (i)

150 conductivity of FY sea ice has a typical range of 0-50 $\mathrm{mS} \mathrm{m}^{-1}$ (Haas, 1997) but this can be assumed negligible relative to the much higher conductivities of the SIPL and the seawater, in which the EM field will preferentially propagate (Haas, 1997; Haas et al., 2009).

The $Q$ response measured by the EM31 is pre-calibrated by the manufacturers and requires a conversion from apparent conductivity in $\mathrm{mS} \mathrm{m}^{-1}$ to $\mathrm{ppm}$. The $I$ response is not pre-calibrated and a calibration factor and offset determined from the drill

155 hole measurements is applied before inverted ice thicknesses are obtained (Irvin, 2018). Field measured $I$ (calibrated) and $Q$ value pairs made with the EM31 at drill hole sites are then compared with forward modelled values in a 'brute force' inversion to obtain the best-matching total ice and SIPL thickness pairs. The 'brute force' inversion applied by Irvin (2018) is a model-based gridsearch method which determines the best-matching forward model by minimising 'the distance between two elements in a metric space' between synthetic and observed data. The Root Mean Square Error between drill hole measured, and inverted total ice and SPL thicknesses is used to assess the quality of the inversion.

For the EM spatial distribution survey and the WSN time-series, 63 coincident drill hole measurements and EM field measured $I$ and $Q$ value pairs were used to calibrate $I$ measured by the EM31 prior to the model inversion. EM measurements of FY (44 drill holes) and SY (19 drill holes) fast ice were then processed separately with forward modelled SIPL thickness ranges of 0-10 m and 0-15 m, respectively. The best matching SIPL bulk conductivity values obtained for the FY and SY ice were $800 \mathrm{mS} \mathrm{m}^{-1}$ and $1000 \mathrm{mS} \mathrm{m}^{-1}$, respectively. For the spatial EM surveys, we removed the snow layer from the inverted total ice thickness using the same method as Brett et al. (2020b) to obtain sea ice thickness only and to facilitate a comparison with the four years of EM westeast transects from that study. The SIMBS EM time-series data were calibrated using the four drill hole measurements made at the site over winter (sect. 2.2) and this is described in more detail in sect. 3.3.

Figure 2 shows forward modelled curves of $Q$ versus $I$ for a SIPL bulk conductivity of $900 \mathrm{mS} \mathrm{m}^{-1}$. Thinner or thicker total ice and SIPL result in larger or smaller $I$ and $Q$ responses, respectively, and both responses are non-linear. Importantly, increases in SIPL thickness drive a larger response in I relative to $Q$ (Haas et al., 2020; Irvin, 2018). Over thicker total ice and SIPL, the signalto-noise ratio is lower and the ability to detect changes in thickness is reduced. Errors in the inversion manifest in the combined thickness of the total ice and the SIPL with a mean relative deviation of 10\% (Irvin, 2018). 
https://doi.org/10.5194/tc-2021-61

Preprint. Discussion started: 17 May 2021

(c) Author(s) 2021. CC BY 4.0 License.

(c) (i)

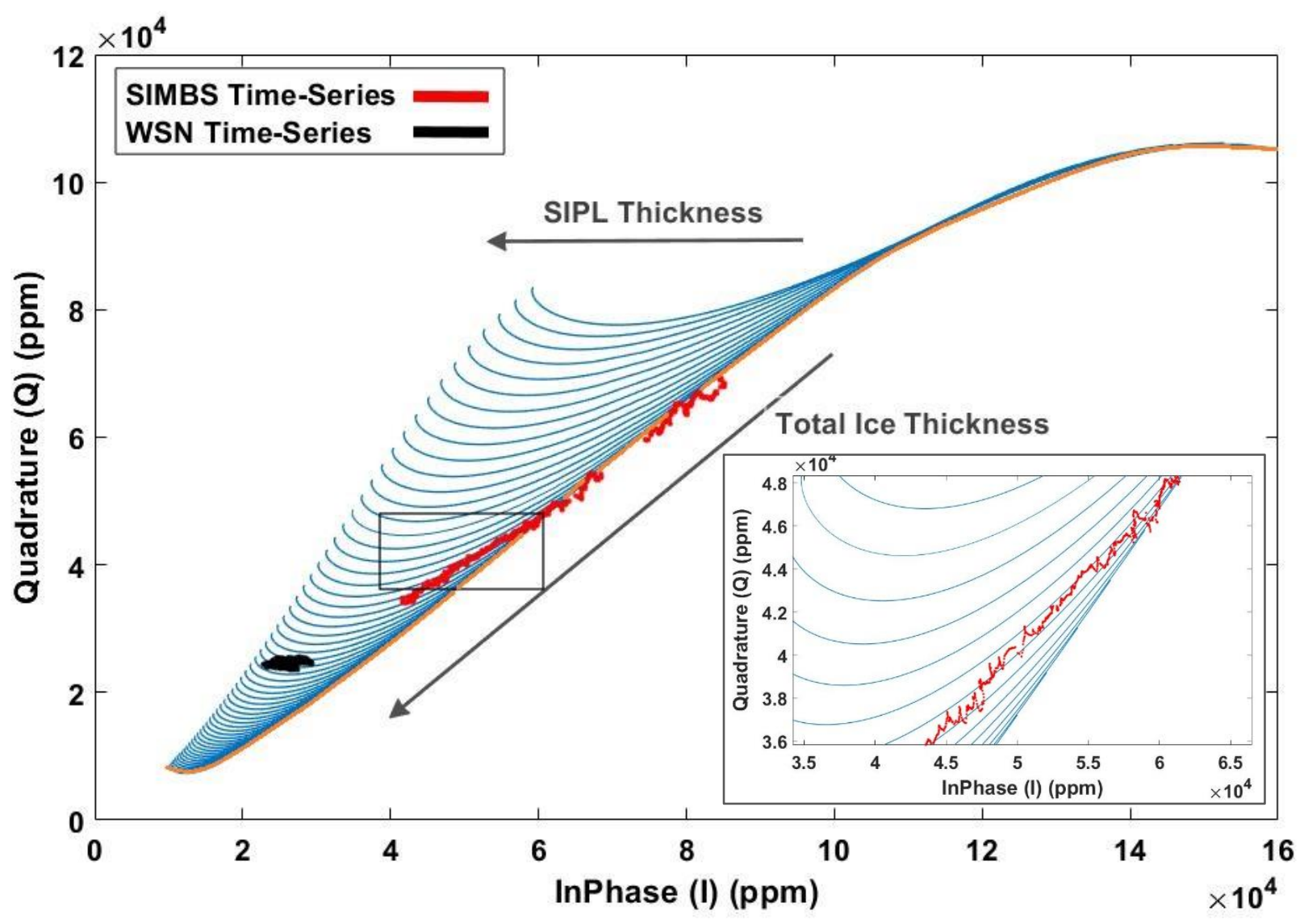

175 Figure 2. Forward modelled curves of quadrature $(Q)$ versus in-phase (I) for a SIPL bulk conductivity of $900 \mathrm{mS} \mathrm{m}^{-1} \mathrm{and}$ total ice thickness (i.e., consolidated ice and snow, 0.5-6 m) and SIPL (0-10 m) thicknesses in $0.10 \mathrm{~m}$ resolution for clarity. The orange curve illustrates total ice thickness with $0 \mathrm{~m}$ SIPL. Field measured $Q$ and $I$ data from the SIMBS (temperaturecorrected) (red) and WSN (black) EM time-series are shown. Inset shows SIMBS data plotted in the forward model.

\subsection{Tidal height in McMurdo Sound.}

180 We investigated whether temporal variability observed in the SIPL correlated with the oscillation of the tides. The tides in McMurdo sound are diurnal with a 13.66-day spring-neap cycle (Goring and Pyne, 2003). We compared the EM time-series measurements of SIPL thickness from the WSN site with tidal height time-series generated using the 2008 Circum-Antarctic Tidal Simulation model CATS2008_opt (CATS) (Padman et al., 2008) and corrected for ocean tide loading of the Earth's crust using the TPXO6.2 load tide model (Egbert and Erofeeva, 2002). The times of the repeat EM surveys on the Centre transect and the SSG surveys were identified on tidal height time-series. We used CATS generated tidal height as opposed to modelled current velocities in our analyses because the model cannot accurately predict the latter for a given time and place (Padman et al., 2003). Tidal height is therefore discussed with respect to tidal-induced current patterns previously observed in McMurdo Sound in sect. 4.4. 
https://doi.org/10.5194/tc-2021-61

Preprint. Discussion started: 17 May 2021

(c) Author(s) 2021. CC BY 4.0 License.

(c) (i)

\section{Results}

1903.1 Spatial distributions of ice shelf-influenced fast ice and the SIPL

The spatial distributions of snow, sea ice and SIPL thickness are shown in Fig. 1. In Fig. 3, we display the EM profiles and drill hole measurements of snow, fast ice and SIPL thickness along the Northern, Centre, and Southern transects from November 2018 with those carried out by Brett et al. (2020b) in November 2011, 2013, 2016 and 2017.

In November 2018, the fast ice in McMurdo Sound consisted of a 7-15 km wide band of SY ice that ran parallel to the MIS in the

195 south and more typical FY ice in the north (Fig. 1b). The spatial distribution of the SIPL (Fig. 1c) was characteristic of McMurdo Sound, with very thick accumulations in the main region of ISW outflow in the centre and southwest. Snow deposition (Fig. 1a) was typical for McMurdo Sound with deeper snow ( 0.2-0.4 m) in the east and southeast, lower deposition in the centre $(\sim 0.10$ $\mathrm{m})$, and a sparse dusting in the west and northwest.

The thinnest fast ice $(1.60 \mathrm{~m})$ and SIPL $(0.06 \mathrm{~m})$ were measured in drill holes in the northeast at longitude $166^{\circ} \mathrm{E}$ on the Northern

200 transect (Fig. 3a). The maximum FY fast ice thickness $(\sim 2.7 \mathrm{~m})$ was observed with EM at longitude $165.4^{\circ} \mathrm{E}$ on the Centre transect (Fig. 3b). We surveyed fast ice and SIPL thickness to the western coastline on the Centre transect (Fig. 3b) and determined the full width of the thickest mass of SIPL (i.e., $>1 \mathrm{~m}$ ) on that latitude to be $\sim 40 \mathrm{~km}$. The Southern transect was carried out on the SY fast ice (Fig. 3c). The thickness of the SY ice ranged from $3.34 \mathrm{~m}$ at the most westerly field site $\left(164.8^{\circ} \mathrm{E}\right)$ to a maximum of $4.15 \mathrm{~m}$ in the centre $\left(165.6^{\circ} \mathrm{E}\right)$, and decreased in thickness towards the east. At the SIMBS site $\left(166.655^{\circ} \mathrm{E}, 77.867^{\circ} \mathrm{S}\right)$, the

205 thickness of the SY ice was $2.49 \mathrm{~m}$ on 19 November 2018. A maximum drill hole measured SIPL thickness of $11 \mathrm{~m}$ was measured beneath the Southern transect at longitude $165.6^{\circ}$ E, which was 2-3 times the thickness of the SIPL measured at the same location in November 2017.

The Northwest transect (Fig. 1c and 4) was carried out over a distance of $24 \mathrm{~km}$ along the main northward circulation pathway of the ISW plume and thickest SIPL on 6 November. The southernmost $1.5 \mathrm{~km}$ of this transect measured $4 \mathrm{~m}$ of SY ice with 8-11 m of SIPL. Beneath the FY ice, the SIPL decreased linearly to the north (from $\sim 5 \mathrm{~m}$ to $\sim 2 \mathrm{~m}$ ) over a distance of $23 \mathrm{~km}$. This equated to a decrease in SIPL thickness of $\sim 0.13 \mathrm{~m} \mathrm{~km}^{-1}$. The EM measured FY fast ice thickness increased from $2.5 \mathrm{~m}$ to $2.8 \mathrm{~m}$ to the north. However, the fast ice in the north consisted of refrozen floes and was relatively rough and deformed. 
https://doi.org/10.5194/tc-2021-61

Preprint. Discussion started: 17 May 2021

(c) Author(s) 2021. CC BY 4.0 License.
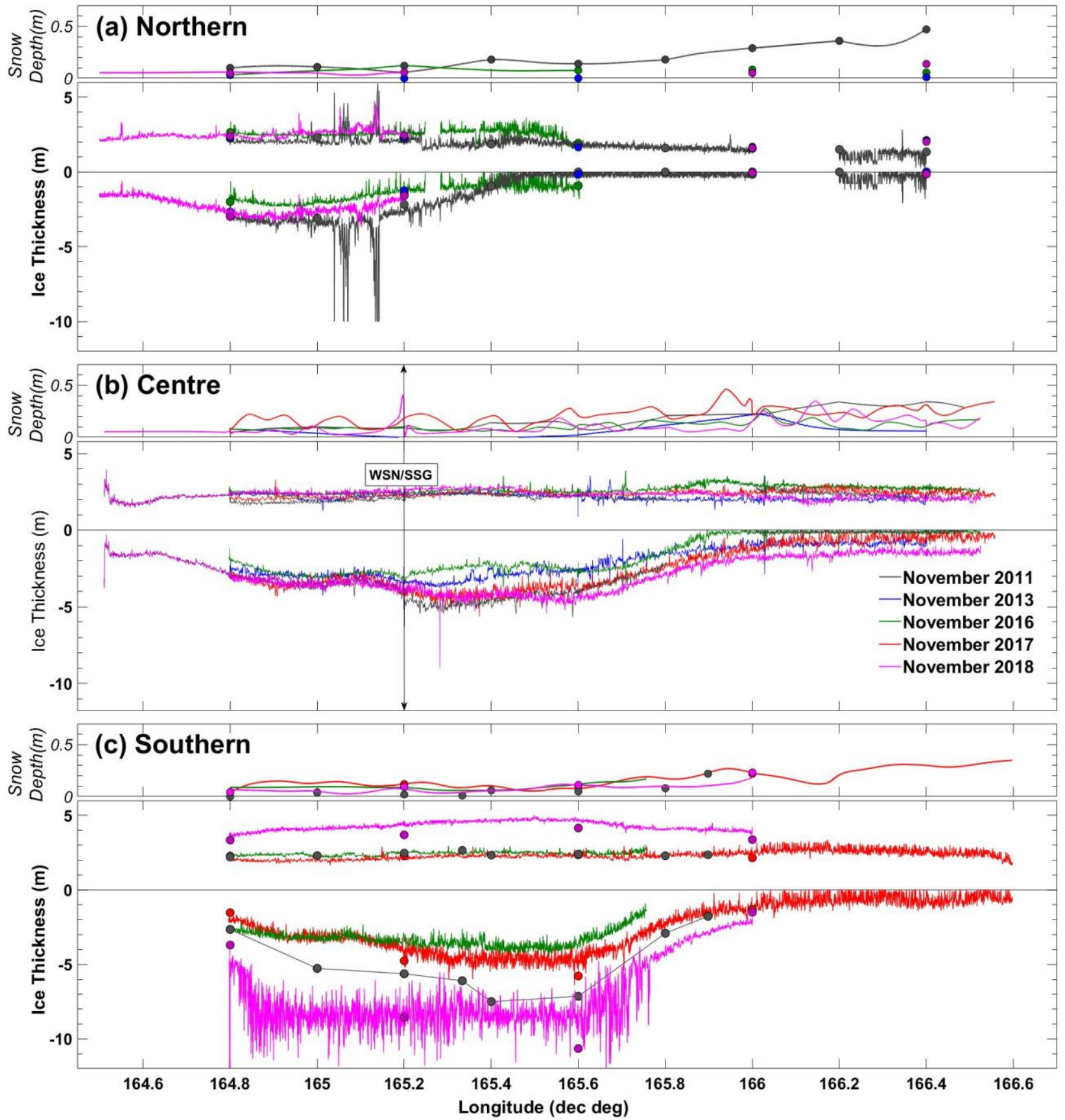

Figure 3. EM measured sea ice (snow layer removed) and EM SIPL thicknesses and average drill hole measured sea ice and SIPL thicknesses at field sites (circles) with spline interpolated and drill hole snow depth along the (a) Northern $\left(77.667^{\circ} \mathrm{S}\right)$, (b) Centre $\left(77.767^{\circ} \mathrm{S}\right)$, and (c) Southern $\left(\mathbf{7 7 . 8 3 3}^{\circ} \mathrm{S}\right)$ west-east transects shown in Fig. 1c from November 2011 (grey), 2013 (blue), 2016 (green), 2017 (red) (Brett et al., 2020b) and 2018 (pink). The location of the WSN EM time-series and SSG survey is shown in (b). For clarity, sea ice and SIPL thicknesses are given in positive and negative values, respectively. Snow depth is displayed with a different $y$-axis scale and is better resolved on the Centre transect in 2016, 2017 and 2018 as measurements were made at 1-km spacing. The panels are approximately $55 \mathrm{~km}$ from west to east. 


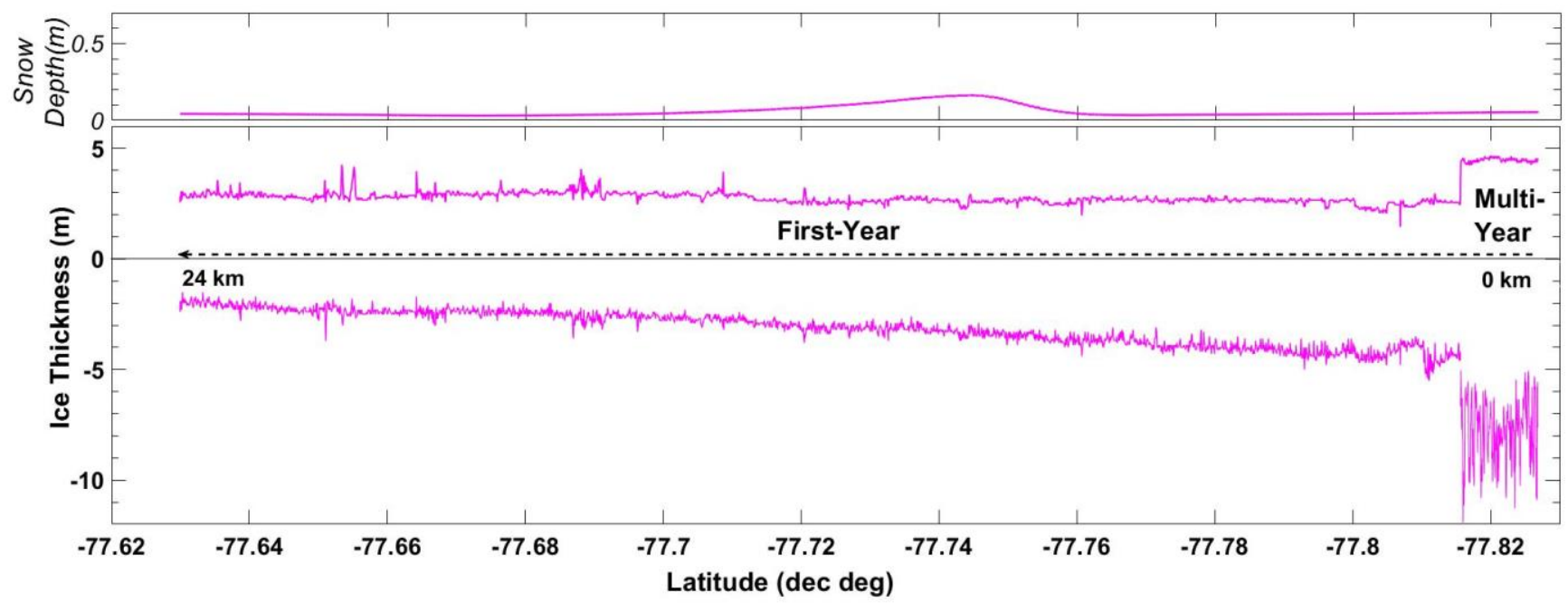

225 Figure 4. EM measured sea ice and SIPL thicknesses with snow depth along the $24 \mathrm{~km}$ Northwest transect (Fig. 1c) along the main circulation pathway of the ISW plume and thickest SIPL on 6 November 2018.

Figure 5 shows an example profile of snow depth, EM-derived total ice, EM sea ice and SIPL thicknesses across the centre of the Small-Scale Grid (SSG) from west to east. Snow depth varied from zero to a few centimeters in the south of the SSG, to large and deep snow drifts of up to $0.35 \mathrm{~m}$ with a north-south orientation in the centre (Fig. 5a). The depth and distribution of the snow did not change significantly over the survey period. EM surveys sampled at $1 \mathrm{~Hz}$ and $5 \mathrm{~Hz}$ resulted in measurements every 2.5 $\mathrm{m}$ and $\sim 0.3-0.4 \mathrm{~m}$, respectively. Prominent undulations were observed in the draft of the SIPL on both north-south and east-west grid lines with $\sim 30-50 \mathrm{~m}$ wavelengths and amplitudes of $\sim 0.3-0.6 \mathrm{~m}$.

Integrated volumes of EM measured sea ice and SIPL within the boundary of the SSG were calculated at four points on a springneap tidal cycle from 4-18 November, and are shown in Fig. 6c with the tides in Fig. 6b. Over the 14-day period, the volume of sea ice within the SSG increased marginally by $\sim 2.5 \%$ from $120,800 \mathrm{~m}^{3}$ to $123,700 \mathrm{~m}^{3}$. The bulk volume of SIPL (i.e., solid ice fraction and interstitial brine volume) increased substantially in the same time period by $\sim 32 \%$, from $151,500 \mathrm{~m}^{3}$ to $200,000 \mathrm{~m}^{3}$. Larger increases in SIPL volume were observed predominately over neap tides between 4 and 10 November, and the beginning of neap tides between 14 and 18 November, relative to smaller increases observed predominately over spring tides between 10 and 14 November. The average thickness of the sea ice and SIPL within the boundary of the SSG increased by $0.06 \mathrm{~m} \mathrm{(2.58-2.64}$ $\mathrm{m})$, and by $1.03 \mathrm{~m}(3.24-4.27 \mathrm{~m})$, respectively over the 14-day period. 

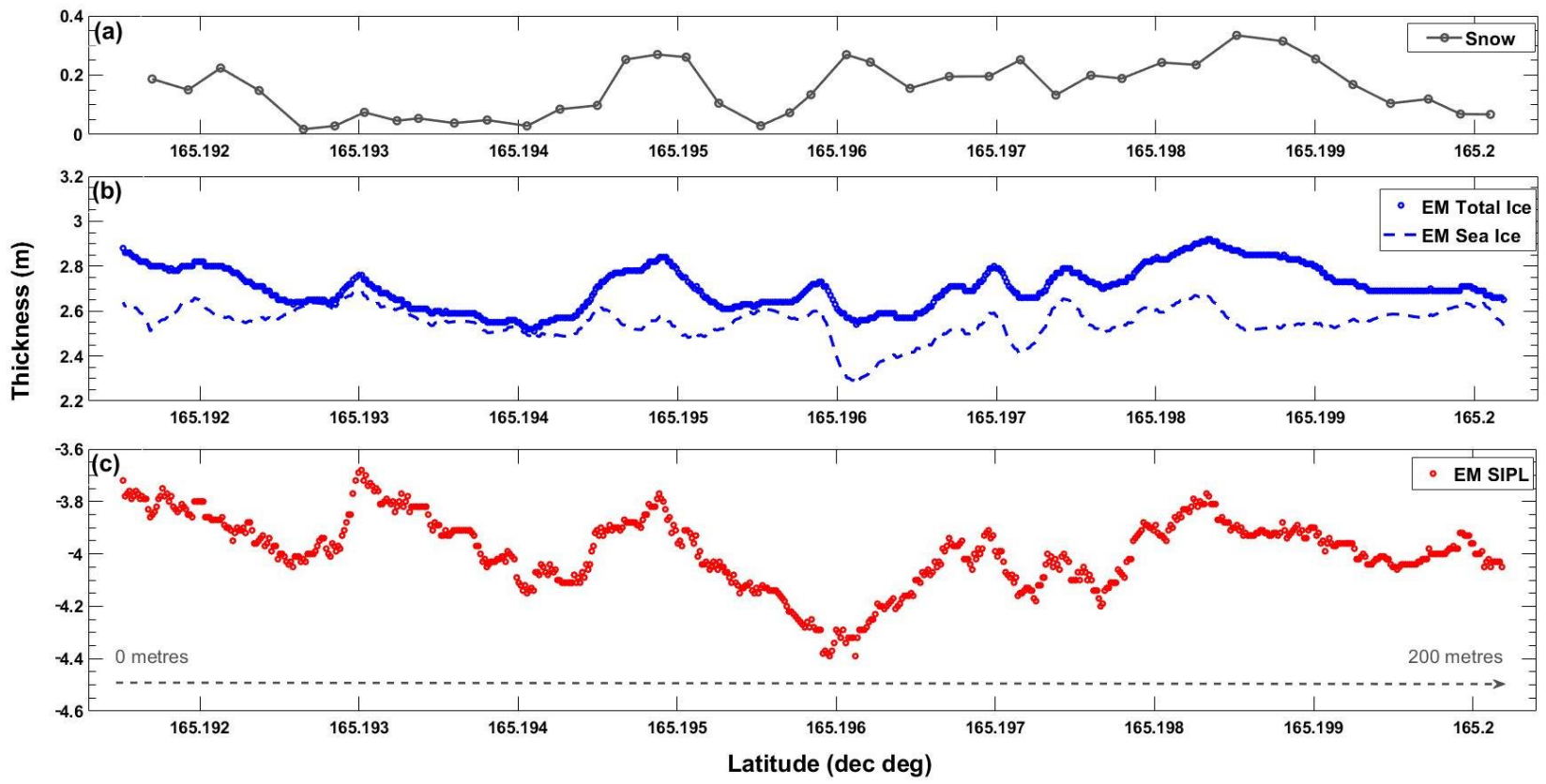

Figure 5. Example profile of (a) snow depth sampled at $5 \mathrm{~m}$ intervals, (b) EM total ice and EM sea ice (snow layer removed) thicknesses, and (c) EM SIPL thickness on a $200 \mathrm{~m}$ west-east transect across the centre of the Small-Scale Grid (SSG) survey at $165.2^{\circ} \mathrm{E}, 77.767^{\circ} \mathrm{S}$. The EM survey was carried out with a sampling frequency of $5 \mathrm{~Hz}$ (i.e. $\sim 0.3-0.4 \mathrm{~m}$ sample spacing) on 14 November 2018.

\subsection{Spatial and temporal variability of the SIPL from repeat EM surveys on the Centre transect}

In 2018, the Centre transect was fully surveyed with EM on 1 and 19 November and partially surveyed a further four times. Each survey is colour-coded in Fig. 6a and their times are displayed on a tidal height curve in Fig. 6b. EM derived sea ice and SIPL thicknesses showed good agreement with drill hole measurements carried out between 3 and 19 November. SIPL thickness increased significantly between 1 and 19 November. Over the 18 days, the SIPL thickness increased by $\sim 0.6 \mathrm{~m}$ in the west (i.e., 164.8-165. $0^{\circ} \mathrm{E}$ ), and $\sim 1.4 \mathrm{~m}$ in the centre (i.e., 165.3-165. $6^{\circ} \mathrm{E}$ ) eastward of where the WSN and SSG were located. This equates to an average daily SIPL growth rate of $0.03 \mathrm{~m}$ in the west and $0.08 \mathrm{~m}$ in the centre. The first survey on the 1 November (green) was carried out on a spring flood tide and the last on a neap ebb tide on the 19 November (magenta).

The partial EM surveys provided additional information on SIPL variability which we compare with the tides between 1 and 19 November. The survey on the 6 (yellow) was carried out on a neap ebb tide and showed 0.4-0.6 m of SIPL growth relative to the 1 (green). The five-day period between the 1 and the 6 November was dominated by neap tides. On a spring ebb tide on the 7 (blue), the SIPL increased substantially relative to the survey on the 1 (green) and had expanded further east. The SIPL did not increase appreciably on the partial survey carried out on the 9 (burgundy) nor on the 13 (red) during spring tides (the surveys on 9 and 13 November are not shown in Fig. 5a for clarity). The consistency in the thickness of the EM measured sea ice in all surveys supports the interpretation of variability in SIPL thickness over the 18-day survey period. 
https://doi.org/10.5194/tc-2021-61

Preprint. Discussion started: 17 May 2021

(c) Author(s) 2021. CC BY 4.0 License.
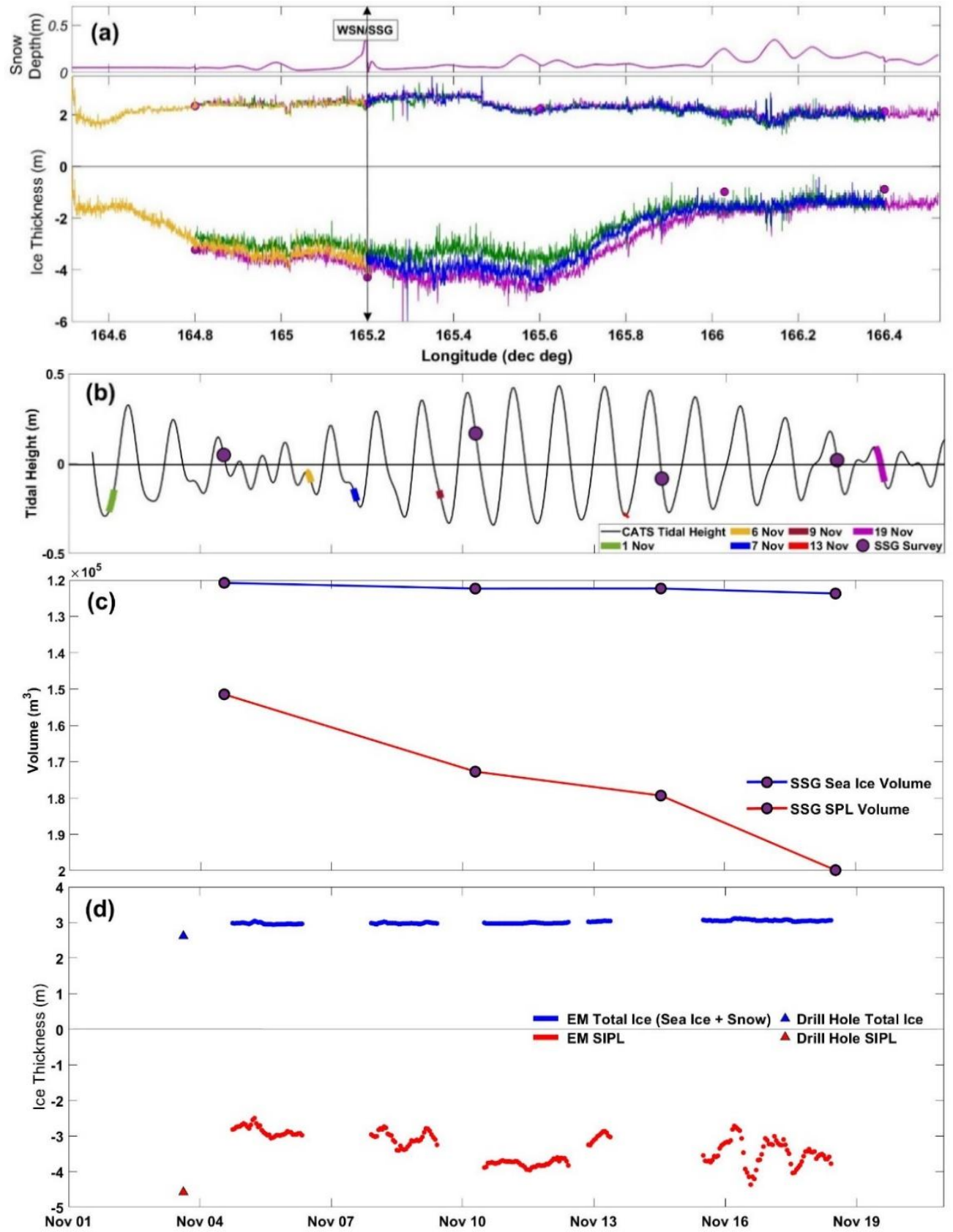

Figure 6. Temporal variability in the SIPL on (a) the Centre transect with EM sea ice and SIPL surveyed on the 1 and 19 fully, and partially on the 6, 7, 9, and 13 November (EM surveys on the 9 and 13 are not shown in (a) for clarity). Drill hole measurements (circles) carried out between 3-19 November 2018 are also shown. The times (NZT) of the repeat Centre transects are colour-coded and displayed with SSG survey times (purple circles) on (b) CATS generated tidal height. (c) Integrated volumes of EM sea ice and SIPL surveyed at $1 \mathrm{~Hz}$ within the boundary of the SSG. The y-axis scale is reversed for easier comparison with the SIPL in (d). (d) EM time-series of EM total ice (sea ice plus snow) and SIPL at the Western Spring-Neap (WSN) site located at $165.2^{\circ} \mathrm{E}$ on (a) the Centre transect and at the south-eastern corner of the SSG with drill hole measurements of total ice and SIPL thickness made on 3 November 2018. 


\subsection{EM time-series measurements of ice shelf-influenced fast and the SIPL.}

In the EM time-series measurements, $I$ and $Q$ changed over time with 1) the growth of fast ice and SIPL, and 2) the oscillation of the tides. The growth of the SIPL and tidal induced variability have never been recorded with EM before and are of significant interest for understanding the processes affecting its formation. An additional effect on $I$ and $Q$ was observed at the SIMBS with 3) large variations in air temperature over winter $\left(-48\right.$ to $\left.-4^{\circ} \mathrm{C}\right)$. This temperature effect on the EM31 instrument was unwanted and we sought to remove it in Appendix A. At the WSN site, the range and extremes of air temperature in late spring $\left(-12\right.$ to $+7^{\circ}$ C) were lower and there was minimal temperature effect (refer to Appendix A) and we applied no temperature correction. We present the EM time-series of total ice or sea ice (i.e., no snow layer) and SIPL thicknesses recorded at the SIMBS and the WSN sites. We then quantify the magnitude of change in $I, Q$ and SIPL thickness observed with the tides in the WSN time-series.

\section{Over winter SIMBS EM time-series}

The temperature-corrected EM times-series of sea ice (not including the snow layer as the instrument was deployed on the sea ice) and SIPL thicknesses recorded over winter at the SIMBS are displayed in Fig. 7 with drill hole measurements, tidal height and southwesterly to easterly $\left(45-270^{\circ}\right)$ hourly wind speeds recorded at an electronic weather station at Scott Base (Fig. 1a). A forward model with a SIPL bulk conductivity of $900 \mathrm{mS} \mathrm{m}^{-1}$ was determined from the four drill hole measurements and brute force inversion of the temperature-corrected $I$ and $Q$ data (Fig. 2). Drill hole thicknesses of the SY ice and the SIPL on the first day of deployment (8 August 2018) were $1.76 \mathrm{~m}$ and $0.13 \mathrm{~m}$, respectively, increasing to $2.40 \mathrm{~m}$ of sea ice and $1.34 \mathrm{~m}$ of SIPL by 19 November. This equates to $0.64 \mathrm{~m}$ of sea ice ( $\sim 0.6 \mathrm{~cm}$ per day) and $1.21 \mathrm{~m}$ of SIPL ( $\sim 1.2 \mathrm{~cm}$ per day) growth over 105 days.

The EM sea ice and SIPL thicknesses were overestimated relative to drill hole measurements by $\sim 20 \%$ and $\sim 30 \%$, respectively. However, fast ice and SIPL growth over winter were well captured in the EM time-series. In early October, substantial increases in SIPL thickness co-occurred with a prolonged southerly storm that drove the formation of the McMurdo and Ross Sea polynyas (observed in Sentinel-1 SAR and NASA Worldview MODIS satellite images) on at least 7 days between 1 and 10 October.

An effect of the SIMBS inversion became apparent once the SIPL persistently exceeded $\sim 0.5 \mathrm{~m}$ thickness where the time-series of inverted EM-derived sea ice and SIPL thickness co-varied over diurnal timescales. Figure 2 shows that prior to the SIPL forming, the field-measured $I$ and $Q$ data points plotted nearest to the curve in the forward model which corresponds to sea ice thickness only with no SIPL $(0 \mathrm{~m})$. Once the SIPL reached a thickness of $\sim 0.5 \mathrm{~m}, I$ decreased sufficiently that the data points moved to a highly sensitive region in the forward model where the curves are closely spaced, and a small change in $I$ or $Q$ will produce a large change in thickness. As $I$ and $Q$ changed with the tides, the $Q-I$ ratio oscillated between forward modelled curves of total ice and SIPL thickness. 

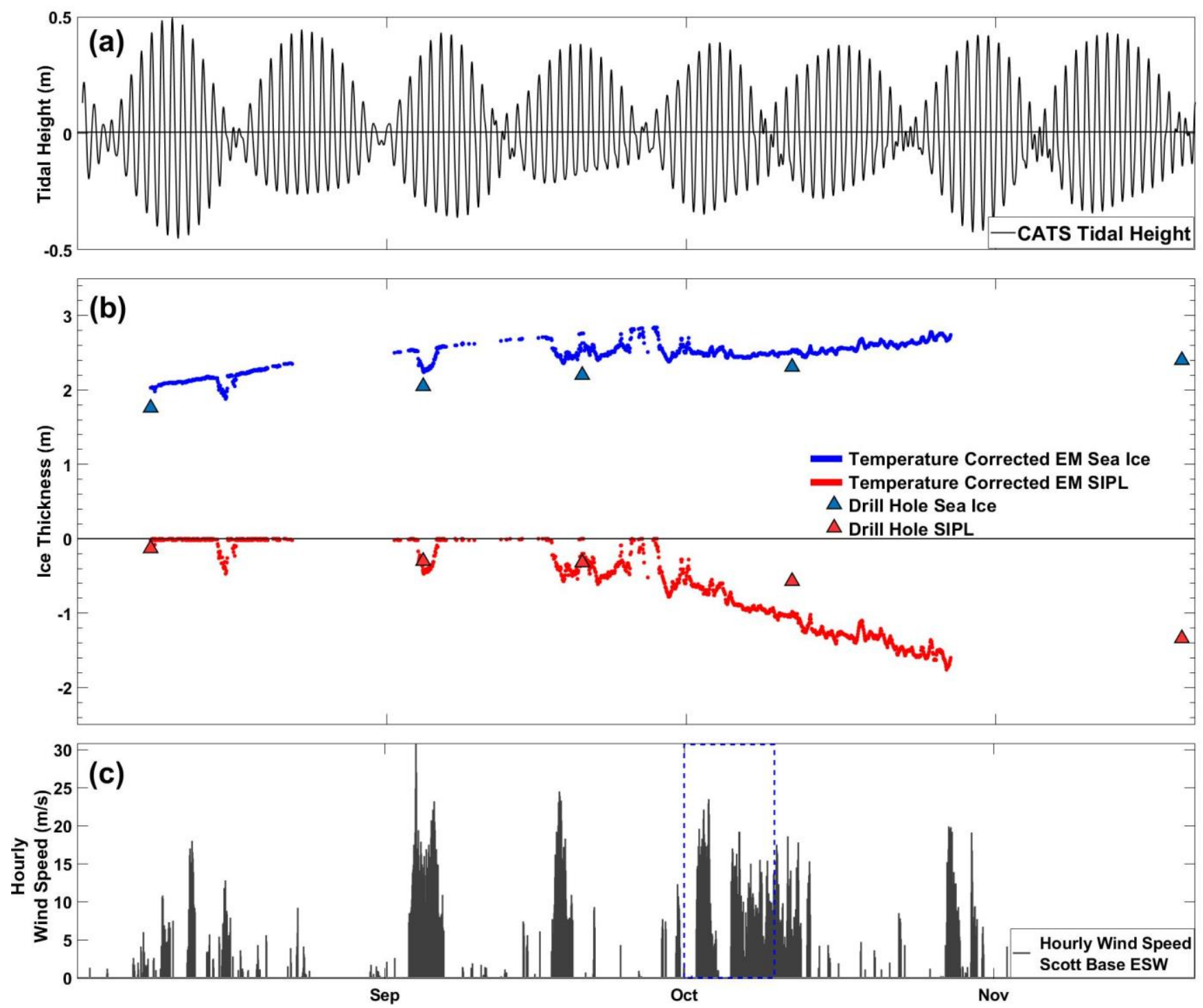

Figure 7. Times-series of (a) CATs generated tidal height, (b) temperature-corrected EM sea ice and EM SIPL thickness recorded over winter at the SIMBS in the Hut Point Peninsula region from 8 August to 27 October 2018 with drill hole measurements of sea ice and SIPL thickness (triangles), and (c) southwesterly to easterly $\left(45-270^{\circ}\right)$ hourly wind speeds from the Scott Base electronic weather station (retrieved on the 26 August 2019: http://cliflo.niwa.co.nz). The blue dashed box outlines the 1-10 October 2018 when the McMurdo and Ross Sea polynyas were observed on at least 7 days.

\section{Late spring WSN EM time-series}

The late spring WSN EM times-series (4-18 November 2018) of total ice (i.e., sea ice plus snow layer) and SIPL thicknesses are displayed in Fig. 6d with tidal height in Fig. 6b. On the 3 November, the drill hole measured total ice and SIPL were $2.62 \mathrm{~m} \mathrm{(2.42}$ $\mathrm{m}$ sea ice plus $0.20 \mathrm{~m}$ snow) and $4.58 \mathrm{~m}$ directly beneath the EM31, and a mean of $2.51 \mathrm{~m}$ ( $2.44 \mathrm{~m}$ sea ice plus $0.07 \mathrm{~m}$ snow $)$ and 
https://doi.org/10.5194/tc-2021-61

Preprint. Discussion started: 17 May 2021

(c) Author(s) 2021. CC BY 4.0 License.

(c) (i)

$3204.28 \mathrm{~m}$ from the five drill hole measurements made at that field site. The EM measured total ice and SIPL were $2.98 \mathrm{~m}$ and 2.82 $\mathrm{m}$ at the start of the time-series, respectively, and increased to $3.06 \mathrm{~m}$ and $3.78 \mathrm{~m}$ at the end. The $14 \%$ overestimate in total ice thickness is within expected relative deviation (Irvin, 2018). The $\sim 40 \%$ underestimate in EM-derived SIPL thickness of $\sim 1.8 \mathrm{~m}$ could be a result of non-uniformities in the density of SIPL which we observed in the resistance of the tape measure when carrying out drill hole measurements. We estimated a less dense horizon of $\sim 1 \mathrm{~m}$ thickness approximately $1 \mathrm{~m}$ from the base of the SIPL.

Over the 14-day period, EM derived total ice and SIPL thicknesses increased by $0.08 \mathrm{~m}$ and $0.94 \mathrm{~m}$, respectively. This magnitude of SIPL growth was comparable to the increase in mean SIPL thickness observed at the SSG $(1.03 \mathrm{~m})$ and in the repeat Centre transect surveys on the 1 and 19 November $(1.4 \mathrm{~m})$, several kilometres to the east (165.3-165.6 $\left.{ }^{\circ} \mathrm{E}\right)$. Diurnal variability in the thickness of the SIPL was observed. However, the EM total ice and SIPL thicknesses did not co-vary. The SIPL was thicker at

$330 \sim 4.6 \mathrm{~m}$ and the $Q$ to $I$ ratio thus plotted in a region of the forward model (Fig. 2) where the model curves are well separated and the inversion of thicknesses is more distinct.

The magnitude of change in $I, Q$ and SIPL thickness at the WSN over the tidal range of each flood (positive from trough to peak) and ebb (negative from peak to trough) spring and neap tide was quantified and is shown in Fig. 8 with linear fits applied. Opposing trends were observed in $Q$ and $I$ with the tides (Fig. 8a). $I$ decreased on ebb tides and increased on flood tides. In contrast, $Q$ increased on ebb tides and decreased on flood tides. Changes in $I$ and $Q$ were largest at maximum ebb tidal ranges of $-0.7 \mathrm{~m}$. during spring tides. SIPL thickness increased over both spring and neap ebb tides (Fig. $8 \mathrm{~b}$ ) by up to $+0.5 \mathrm{~m}$ but then decreased by $-0.4 \mathrm{~m}$ during spring flood tides. In contrast, neap flood tides with tidal ranges of $+0.2 \mathrm{~m}$ or lower caused small increases in SIPL thickness resulting in net growth over neap tidal cycles.

We investigated how variability in seawater conductivity would affect $I, Q$ and SIPL thickness at the WSN site. We forward modelled a three-layer case consisting of constant total ice thickness of $2.7 \mathrm{~m}$ (i.e., $2.5 \mathrm{~m}$ of sea ice plus $0.2 \mathrm{~m}$ of snow), and constant SIPL thicknesses of $3 \mathrm{~m}$ or $4 \mathrm{~m}$, for a fixed bulk SIPL conductivity of $800 \mathrm{mS} \mathrm{m}^{-1}$, and a range of seawater conductivities from 2400-3000 mS m${ }^{-1}$. The resultant $I$ and $Q$ values were then compared (Delta ppm) to the assumed $2700 \mathrm{mS} \mathrm{m}^{-1}$ seawater 345 conductivity used in the base forward model in Fig. 8c. The trend of opposing change in $I$ and $Q$, with flood and ebb tides, fit the pattern of changing seawater conductivity, (i.e., decreasing seawater conductivity on ebb tides, and increasing seawater conductivity on flood tides). For spring ebb tidal ranges of $-0.7 \mathrm{~m}$, the magnitude of change in $I$ and $Q$ would require an approximate decrease of $150 \mathrm{mS} \mathrm{m}^{-1}$ in seawater conductivity, to $2550 \mathrm{mS} \mathrm{m}^{-1}$, if the SIPL assumed by the model was $4 \mathrm{~m}$. For flood spring tidal ranges of $+0.7 \mathrm{~m}$, the magnitude of change in $I$ and $Q$ would require an increase in seawater conductivity of 350 approximately $100 \mathrm{mS} \mathrm{m}^{-1}$, if the SIPL assumed by the model was $4 \mathrm{~m}$ thick. We further explore the plausibility of variability in seawater conductivity due to changes in seawater salinity or temperature in sect. 4.5. 
https://doi.org/10.5194/tc-2021-61

Preprint. Discussion started: 17 May 2021

(c) Author(s) 2021. CC BY 4.0 License.

To determine if variability in the bulk conductivity of the SIPL would produce the observed changes in $I$ and $Q$, and SIPL thickness, multiple forward models were run for a range of SIPL bulk conductivity values from $700-900 \mathrm{mS} \mathrm{m}^{-1}$, for a constant sea ice thickness of $2.7 \mathrm{~m}$, and SIPL thicknesses of $3 \mathrm{~m}$ and $4 \mathrm{~m}$ (Fig. 8d). The forward modelled $I$ and $Q$ values were then compared (Delta ppm) to the $800 \mathrm{mS} \mathrm{m}^{-1}$ bulk SIPL conductivity determined for the WSN time-series. Increasing the bulk conductivity of the SIPL caused concurrent increases in forward modelled $I$ and $Q$. Reciprocally, decreasing the SIPL bulk conductivity resulted in decreases in both forward modelled $I$ and $Q$. As such, variability in the bulk conductivity of the SIPL was unlikely to have driven the observed opposing changes in $I$ and $Q$ with tides.
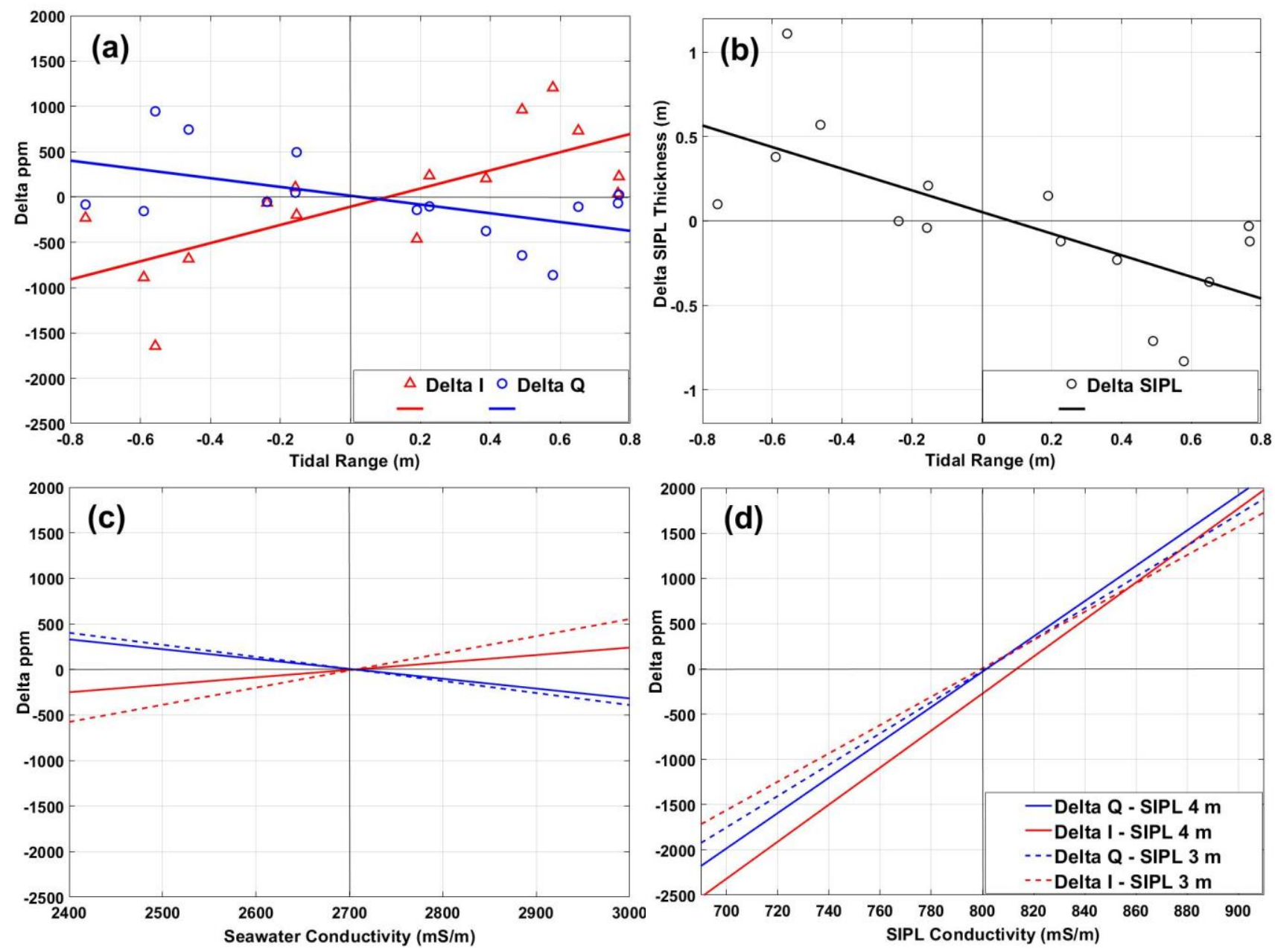

Figure 8. The magnitude of change in (a) $I$ and $Q$ (Delta ppm), and b) SIPL thickness over the tidal range of each flood (positive from trough to peak) and ebb (negative from peak to trough) tidal range in the WSN EM time-series with linear fits applied. Forward modelled $I$ and $Q$ for a three-layer case consisting of constant total ice thickness of $2.7 \mathrm{~m}$ and SIPL thicknesses of $3 \mathrm{~m}$ or $4 \mathrm{~m}$, for (c) a fixed bulk SIPL conductivity of $800 \mathrm{mS} \mathrm{m}^{-1}$ and a range of seawater conductivities from 2400 to $3000 \mathrm{mS} \mathrm{m}^{-1}$, and (d) for a fixed bulk seawater conductivity of $2700 \mathrm{mS} \mathrm{m}^{-1}$ and a range of SIPL bulk conductivity values from 700 to $900 \mathrm{mS} \mathrm{m}^{-1}$. 
https://doi.org/10.5194/tc-2021-61

Preprint. Discussion started: 17 May 2021

(c) Author(s) 2021. CC BY 4.0 License.

(c) (i)

\section{Discussion}

\subsection{Spatial distributions of ice shelf-influenced fast ice and the SIPL}

In November 2018, we observed the typical spatial distribution of thicker ice shelf-influenced fast ice and SIPL in the centre and west of McMurdo Sound which result from circulation of supercooled ISW in McMurdo Sound (Brett et al., 2020b; Langhorne et al., 2015). The full west-east width of the SIPL was determined to be $\sim 40 \mathrm{~km}$ on the Centre transect (Fig. 3b) concurring with airborne EM measurements carried out along the same latitude by Haas et al. (2021) in 2011, 2013, 2016 and 2017. The thick SIPL ( 2 $\mathrm{m})$ observed near the western coastline suggests that significant volumes of supercooled ISW propagate along the Victoria Land coastline.

375 The Northwest transect along the main axial line of the ISW plume showed that SIPL thickness decreased approximately linearly beneath the FY fast ice. This is in agreement with the longitudinal oceanographic profile collected by Hughes et al. (2014) where salinity and temperature increased linearly with distance from the MIS, with a reciprocal linear decrease in the thickness of the supercooled ISW layer. If it is assumed that the SIPL continued to decrease linearly at a rate of $-0.13 \mathrm{~m} \mathrm{~km}^{-1}$ to the northwest (beneath the FY ice), then the SIPL thickness should decrease to a few centimetres approximately $40 \mathrm{~km}$ to the north of the MIS. However, drill holes measurements $\sim 85 \mathrm{~km}$ north of the ice shelf in 2013, 2016, and 2017 observed SIPL thicknesses of 0.1-0.2 m (Brett et al., 2020b; Price et al., 2014) suggesting that supercooled ISW propagates further north or is replenished along the Victoria Land coastline.

The undulations observed in SIPL thickness at the SSG (Fig. 5c) demonstrate the capability of the EM31 instrument to resolve small-scale (metres) features in the SIPL draft, a region which is difficult to observe. Robinson et al. (2017) observed ripple-like structures in the SIPL draft in McMurdo Sound in video footage which they suggested could be formed by a sedimentation process analogous to sand dune formation. The ripples in that study had $\sim 0.30 \mathrm{~m}$ amplitudes and 2-3 m wavelengths, an order of magnitude less than the wavelengths we observed ( 30-50 m) with EM. The EM31 might not have resolved the smaller amplitude waves, or alternatively, the processes forming these features could vary regionally with ocean circulation regimes. The western side of the west-east EM transects shown in Fig. 3 frequently display more apparent noise in SIPL thickness relative to the east. We would generally expect more noise in the east due to surface variability caused by the thicker snow layer (Brett et al., 2020b). This apparent noise in the SIPL in the west could be a real effect resulting from these large undulations in the SIPL draft.

\subsection{The effects of second-year ice}

395 On the Southern transect, the thickest SY ice and SIPL were observed at $\sim 165.6^{\circ} \mathrm{E}$ in the main region of supercooled ISW outflow from the MIS cavity. This thicker fast ice and SIPL were previously observed with EM (Brett et al., 2020b; Haas et al., 2020), and in multiple other studies ranging from oceanographic profiling (Hughes et al., 2014; Lewis and Perkin, 1985; Robinson et al., 2014) to satellite altimetry assessments of fast ice freeboard (Brett et al., 2020a; Price et al., 2013). 
https://doi.org/10.5194/tc-2021-61

Preprint. Discussion started: 17 May 2021

(c) Author(s) 2021. CC BY 4.0 License.

(c) (i)

The SY ice regime likely contributed to the very thick SIPL of $11 \mathrm{~m}$ observed in November 2018. The longer temporal persistence of the two-year-old fast ice would allow a thicker SIPL to form. Additionally, the SY ice will have lower conductive heat flux to the atmosphere (Gough et al., 2012) and the slower freezing rate of the thicker ice would be exceeded by frazil and platelet ice crystal deposition more readily. To the west of longitude $166^{\circ}$ E on the Southern transect, the SIPL in 2018 was 2-3 times the thickness observed in November 2017.

The thickness of the SY ice measured near the MIS in November 2018 varied from $4.15 \mathrm{~m}$ in the centre $\left(\sim 165.6^{\circ} \mathrm{E}\right)$ to $2.40 \mathrm{~m}$ in the east in the Hut Point Peninsula region. This highlights the different regimes in ocean circulation and the distributions of snow, fast ice, and SIPL observed from west to east in McMurdo Sound. The snow coverage in the central region was sparse and varied in depth from 0.04-0.09 $\mathrm{m}$. Deeper snow deposition in the east $(0.2-0.3 \mathrm{~m})$ would insulate the sea ice and hinder thermodynamic growth (Dempsey et al., 2010; Hoppmann et al., 2015a). Additionally, the SIPL and the overlying fast ice would be ablated by the variable currents in the east when warmer water masses from the Ross Sea flow into the MIS cavity in summer (Mahoney et al., 2011; Robinson et al., 2010). The existing SIPL should buffer the base of the sea ice from ocean currents (Hoppmann et al., 2015a; Hoppmann et al., 2015b). A study by Hoppmann et al. (2015b) in Atka Bay near the Ekström Ice Shelf in Queen Maud Land showed that SIPL decreased in thickness when warm water masses inflow in summer. They found that the SIPL protected the base of existing sea ice and prevented significant melting. The SIPL in McMurdo Sound is consistently thinner in the east and would thus have less buffering capacity allowing more ocean-driven melting in summer relative to the west where the SIPL is thicker.

\subsection{Temporal variability of the SIPL with strong southerly winds}

In early October 2018, we observed substantial increases in SIPL thickness in the Hut Point Peninsula region during a prolonged southerly storm which drove the formation of the McMurdo and Ross Sea polynyas (observed in satellite images) suggesting a rapid response to wind-driven surface circulation. We speculate that divergence and upwelling within the McMurdo Sound Polynya could occur as surface waters are advected offshore by strong southerly winds. Upwelling could draw water out from beneath the fast ice and out from the ice shelf cavity. The accelerated rise of ISW from deeper in the cavity and decrease in pressure (Foldvik and Kvinge, 1974; Jordan et al., 2015) would promote supercooling and frazil ice formation which could then be deposited beneath adjacent fast ice. However, it was not possible to determine the mechanism for rapid increases in SIPL thickness with wind forcing without coincident oceanographic observations at the SIMBS.

\subsection{The influence of the tides on ocean circulation and the SIPL in McMurdo Sound}

In the WSN EM time-series, SIPL thickness increased on ebb tides (Fig. 8b) with larger increases observed on spring ebb tides relative to neap ebb tides. However, the larger increases on spring ebb tides were negated on spring flood tides when the SIPL thickness decreased by a similar magnitude (Fig. 8b). During periods of neap tides, net SIPL thickness growth was observed with 
https://doi.org/10.5194/tc-2021-61

Preprint. Discussion started: 17 May 2021

(c) Author(s) 2021. CC BY 4.0 License.

(c) (i)

(Fig. 6a and 6b) showed substantial increases in SIPL thickness over periods of neap tides relative to spring tides where no significant change was observed (Note: EM surveys on 9 and 13 November during spring tides are not shown in Fig. 6a for clarity). At the SSG, the bulk volume of the SIPL (Fig. 6c) increased more over periods of neap tides relative to spring tides.

A distinct trend emerges of SIPL thickness increasing more over ebb tides relative to flood tides, with overall larger net increases

during periods of neap tides relative to spring tides. This trend correlates with the tidal current patterns observed in oceanographic studies where neap and spring ebb tides resulted in northward currents in both the east and west of McMurdo Sound (Leonard et al., 2011; Leonard et al., 2006; Robinson et al., 2010; Robinson et al., 2014). Northward currents during ebb tides would be circulating out from the MIS cavity and would likely be comprised of supercooled ISW which could increase SIPL thickness. In western McMurdo Sound, currents observed at $200 \mathrm{~m}$ depth by Robinson et al. (2014) were consistently northward during neap tides and spring tides. They observed peak northward flow during spring and neap ebb tides, and slower, suppressed northward flow during spring flood tides. Flows were predominately to the north-northwest, out from the MIS cavity, and aligned with the Victoria Land coastline (Robinson et al., 2014). During periods of neap tides, Hughes et al. (2014) observed that the depth of insitu supercooling in the centre and east of McMurdo Sound was greater than periods of spring tide. This would prime the water column for augmented SIPL growth (Mahoney et al., 2011).

\subsection{Potential drivers of variability in the SIPL with the tides}

Three possible scenarios could explain the rapid response observed in $I$ and $Q$, and inverted SIPL thickness with the oscillation of the tides: 1) changes in the conductivity of the seawater, or 2) changes in the bulk conductivity of the SIPL, or 3) a real physical change in the SIPL thickness. Here we explore the plausibility of these scenarios with respect to the EM observations and previously observed tidally-induced current patterns.

\section{Seawater conductivity: salinity and temperature}

At the WSN, the conductivity of the seawater beneath the SIPL would need to change by $100-150 \mathrm{mS} \mathrm{m}^{-1}$ to account for the change in $I$ and $Q$ with the tides. For a fixed seawater temperature of $-1.9^{\circ} \mathrm{C}$ and constant pressure of 15 decibar, a change in seawater conductivity of $100 \mathrm{mS} \mathrm{m}^{-1}$ would require a change in practical salinity of 1.4 (Mcdougall and Barker, 2011). Ranging the temperature of the seawater between $-1.80^{\circ} \mathrm{C}$ and $-2.05^{\circ} \mathrm{C}$ and increasing the pressure to 20 decibar has minimal effect on the magnitude of change in practical salinity $(\sim \Delta 0.01)$. Mahoney et al. (2011) observed an increase in salinity of 1.1 over a 4 month period between June and September 2009 and a maximum change of $\sim 0.5$ over diurnal timescales (estimated from Figure 4 in Mahoney et al. (2011)). This was recorded in the Hut Point Peninsula region in the east where the currents are known to be variable and to oscillate with the tides. Higher variability in salinity would be thus expected in the east relative to WSN site in the

460 west where the currents are predominately northwards and out from the cavity. A change in seawater salinity of 1.4-2.0 with tidal currents on diurnal timescales at the WSN site in the west is thus unlikely and we have shown that a variable temperature range of $-1.80^{\circ} \mathrm{C}$ to $-2.05^{\circ} \mathrm{C}$ has minimum effect. 


\section{Bulk conductivity of the SIPL}

The SIPL is an unconsolidated and porous mass of platelet ice crystals with brine-filled interstices. The bulk conductivity of the SIPL could vary with changes in brine salinity in the connected pore space or the solid ice fraction. However, this is difficult to quantify as ice crystal formation/growth and consequent brine rejection should concurrently increase the solid ice fraction of the SIPL (Dempsey et al., 2010) (i.e., reduce the SIPL bulk conductivity) and increase the salinity of the brine (Robinson et al., 2014) (i.e., increase the SIPL bulk conductivity). Ocean profiling in the west by Robinson et al. (2014) showed that platelet ice crystal formation and growth in supercooled water resulted in brine rejection and boundary layer instability beneath the SIPL. The continuous outflow of supercooled ISW in the west of McMurdo Sound would ensure that this is an ongoing process, and a more periodic occurrence in the east with more variable current directions and water properties with the tides. At the WSN, changes in the forward modelled SIPL bulk conductivity did not match the observed pattern of opposite change in $I$ and $Q$ (Fig. 8d vs. 8a). Considering this with the rapid response to the tides, we infer that changes in SIPL bulk conductivity are unlikely to have caused the observed change in inverted SIPL thickness.

\section{SIPL thickness and Frazil ice events}

Given that the changes described in 1 and 2 are unlikely to account for the observed changes in $I$ and $Q$, the remaining option is a real physical change in SIPL thickness. Variability in SIPL thickness could be driven by movement of freely-floating mobile masses of SIPL at the base as observed by Robinson et al. (2017) which could periodically oscillate back and forth with changing current directions with the tides. However, the currents in the west at the WSN are predominately northwards regardless of the tides (Barry and Dayton, 1988; Hughes et al., 2014; Robinson et al., 2014). Robinson et al. (2014) postulated that brine concentrations could occur within the SIPL if downward drainage was impeded. Inhomogeneities in the mechanical resistance and density of the SIPL were observed beneath the WSN in November 2018. These inhomogeneities could facilitate compression or flooding of the SIPL with the tides but would also influence the bulk conductivity of the SIPL and the integrity of the assumed 3-horizontal layer model (Irvin, 2018) and the propagation of the EM field in the SIPL.

Camera observations of individual platelet ice crystals at the base of the SIPL in 2000 (Smith et al., 2001) and 2003 (Leonard et al., 2006) in the east of McMurdo Sound revealed episodic growth bursts during times of low tidal range. Minimum and maximum platelet ice crystal growth rates were on the order of 1-12 cm per day. This must contribute to the SIPL thickness over long periods of time (i.e., weeks and months) but the growth rates seem unlikely to fully account for the rapid response of the SIPL to the tides or strong southerly wind events. Variability in SIPL thickness could also be driven by episodes of frazil and platelet ice crystal deposition and erosion/melt. Episodic increases in the density of frazil ice suspended in the upper water column have been observed with supercooled ISW outflow from the cavity (Frazer et al., 2020; Leonard et al., 2006), which in turn is promoted more in ebb (both spring and neap) tides and over periods of neap tide cycles. Neap tides drive slower tidal currents which could favour the deposition of frazil ice crystals at the base of the SIPL and increase the thickness. Reciprocally, stronger currents during 

crystals and deposition beneath the fast ice in Atka Bay by Hoppmann et al. (2015b) indicated a continuous background flux of platelet ice crystals with episodic events of very high fluxes of ice crystals of $\sim 1$ hour duration. They observed deposition of the suspended crystals into the porous base of the SIPL which were resuspended with turbulence and strong currents.

In consideration of 1, 2 and 3 and the observed rapid response of the SIPL to the tides, we suggest the most plausible scenario is changes in the thickness of the layer with frazil and platelet ice crystal deposition and erosion/melt. However, without coincident underwater footage and oceanographic measurements of water properties and currents, we cannot conclude why the thickness or properties of the SIPL changed with the tides and what effect the conductive properties of the SIPL and the upper ocean are having on the EM measurement. We forward model a simple subsurface comprised of three horizontal conductive layers: 1) total ice thickness (i.e., consolidated sea ice plus snow thickness), 2) a SIPL, and 3) infinitely deep seawater and use single-frequency EM instrument. In reality, the solid ice fraction, brine volume and salinity, brine layering/pockets and density gradients affect the conductive properties of the SIPL. The properties and structure of the SIPL are inherently difficult to measure without disturbing its natural state and are not well understood. The propagation of the EM field through the SIPL is complex and could vary with spatial and temporal inhomogeneities in the conductive properties or structure of the layer.

Multi-frequency EM techniques could be applied to better constrain the properties of the SIPL and the response of the EM field to inhomogeneities within the SIPL. Hunkeler et al. (2015) used a multi-frequency EM device and forward modelling techniques to quantify the bulk conductivity and solid ice fraction of the SIPL beneath fast ice in Atka Bay. Applying Archie's Law for bulk electrical conductivity, they derived a mean bulk SIPL layer conductivity of $1154 \pm 271 \mathrm{mS} \mathrm{m}^{-1}$ comparable to the $800-1000 \mathrm{mS}$ $\mathrm{m}^{-1}$ observed in this study and ice volume fractions of 0.29-0.43. The method was extended to derive the thickness of the SIPL by applying a drill hole adjusted geophysical inversion of a three-layer forward model (Hunkeler et al., 2016). Although multi-

515 frequency could provide more information on SIPL properties, it requires careful calibration of individual frequencies and is more complex, time-consuming and computationally demanding (Hunkeler et al., 2015).

\section{Conclusion}

The late spring spatial distributions of ice shelf-influenced fast ice and the sub-ice platelet layer have been well described in 520 McMurdo Sound and compared on interannual timescales in previous work by the authors. Temporal variability in the SIPL on diurnal timescales however has not been previously observed nor described in McMurdo Sound or elsewhere on the Antarctic coastline. Here, we present novel EM time-series measurements of the temporal evolution of the SIPL over winter, and variability in the SIPL in the main path of ISW outflow in the west over a spring-neap tidal cycle in the following late spring. The EM instrument successfully captured the growth of ice shelf-influenced fast ice and the SIPL in the Hut Point Peninsula region over 
https://doi.org/10.5194/tc-2021-61

Preprint. Discussion started: 17 May 2021

(c) Author(s) 2021. CC BY 4.0 License.

(c) (i)

winter. Substantial increases in SIPL thickness co-occurred with strong southerly wind events and polynya activity in the region in early spring, suggesting enhanced outflow of supercooled ISW from the ice shelf cavity by wind-driven surface circulation.

In the EM time-series in the main path of ISW outflow in the west in late spring, diurnal variability was observed in the thickness and distribution of the sub-ice platelet layer which correlated with the oscillation of the tides. Significant increases in SIPL thickness were observed on ebb tides in both spring and neap cycles with larger net increases during periods of neap tides. This temporal pattern in SIPL thickness variability matched with tidally-induced currents recorded in previous oceanographic studies, where ebb tides on both neap and spring tides resulted in northward currents in both the east and west of McMurdo Sound. Northward currents would be flowing out from the ice shelf cavity and be comprised of supercooled ISW which would drive increases in SIPL thickness. We considered how changes in the tidal currents could affect the conductive properties of the SIPL and seawater with respect to the EM observations.

The spatial distributions of the thickness of ice shelf-influenced fast ice and the sub-ice platelet layer were additionally assessed in McMurdo Sound in November 2018 with ground-based EM and drill hole surveys, and concurred with a previous four-year dataset (Brett et al., 2020). In high resolution ( 0.3-0.4 m sample spacing) small-scale spatial surveys, prominent undulations

540 were observed in the draft of the SIPL with $\sim 30-50 \mathrm{~m}$ wavelengths and amplitudes of $\sim 0.3-0.6 \mathrm{~m}$ for the first time with EM. A substantially thicker SIPL of up to $11 \mathrm{~m}$ was observed beneath two-year-old fast ice near the ice shelf in the west indicating that the longer temporal persistence and reduced (relative to FY ice) thermal conductivity of the second-year ice facilitated thicker SIPL formation. The variability observed in the SIPL indicated that a combination of the tides, wind-driven polynya activity and the presence of multi-year fast ice influences the circulation of ISW and consequently the evolution of the SIPL over a range of timescales.

EM measures the conductivity of the subsurface which is then converted to fast ice and SIPL thicknesses. Without coincident oceanographic observations, it is only possible to infer the processes at play in the ocean beneath the fast ice that are influencing the SIPL. However, here we consider variability observed in the SIPL with respect to previous oceanographic studies carried out in McMurdo Sound. Coincident oceanographic data collected near the WSN site by collaborators will aid the interpretation of the observed tidally-induced changes in the SIPL, when available. For future EM time-series measurements, oceanographic moorings and underwater cameras should be deployed to monitor the properties of the water column, ocean currents and the base of the SIPL. This would provide critical information on the response of the water column to strong southerly wind events and polynya activity in the western Ross Sea. This could clarify if wind-driven surface circulation and upwelling is drawing ISW out from the 555 ice shelf cavity. Additionally, a heating device should be integrated into the EM time-series set-up to mitigate temperature effects on the EM31 instrument. 
https://doi.org/10.5194/tc-2021-61

Preprint. Discussion started: 17 May 2021

(c) Author(s) 2021. CC BY 4.0 License.

(c) (i)

\section{Appendix A}

In the SIMBS EM time-series, an approximately linear trend was observed as both $I$ and $Q$ decreased with increasing sea ice and

SIPL growth (Fig. A1). Superimposed on the growth trend, diurnal variability in $I$ and $Q$ resulted from the combined effects of the oscillation of the diurnal tides, and the effect of large changes in air temperature on the EM31 instrument. Air temperature measured by the data-logger at the SIMBS over winter ranged from a minimum of $-48^{\circ} \mathrm{C}$ on the 25 August to maximum of $-4^{\circ}$ $\mathrm{C}$ at the end of the time-series on the 26 October. Substantial changes in air temperature occurred over short periods of time, e.g., an increase from $-40^{\circ} \mathrm{C}$ to $-13^{\circ} \mathrm{C}$ was recorded over a 38-hr period on 28-29 September. Figures A1 and A2 show that $Q$ was more affected by changes in air temperature than $I$.

In the latter half of the time-series, air temperature followed a quasi-diurnal pattern, with minimum and maximum temperatures generally observed at night and midday, respectively. The diurnal pattern in air temperature was amplified in October with increasing solar altitude and irradiation. The SIPL also increased substantially in thickness in October and could thus display a stronger tidal signal. The diurnal patterns in both the tides and air temperature (especially October) resulted in a combined signal that was not possible to fully separate. Therefore, the following correction applied to remove the unwanted temperature effect would have partially removed the tidal signal.

$I$ and $Q$ at all points on the tidal cycle in October were de-trended for the linear growth trend and then plotted against air temperature (Fig. A2). The linear fits to $I$ and $Q$ versus temperature provided an average response across the large range of temperatures observed. $Q$ had a stronger correlation with changing air temperature than $I$. The entire time-series of $I$ and $Q$ were then corrected using their respective equations of the line (Fig. A2). The ratio of $Q$ to $I$ is specific to pairs of total ice and SIPL thicknesses (Irvin, 2018). Applying separate temperature corrections to $Q$ and $I$ could change the $Q-I$ ratio, and result in a poor forward model selection. To assess the temperature corrections applied to $I$ and $Q$, the raw-uncorrected $Q-I$, and temperaturecorrected $Q-I$ ratios were compared. Figure A1 shows a comparison of raw-uncorrected $I$ and $Q$, with temperature-corrected $I$ and $Q$ with their respective $Q-I$ ratios. The raw-uncorrected and temperature-corrected $Q-I$ ratio values were of similar magnitude with less variability in the temperature-corrected $Q-I$ ratio time-series as was desired.

At the WSN site, the range and extremes of temperatures measured by the data-logger in late spring $\left(-12\right.$ to $\left.+7^{\circ} \mathrm{C}\right)$ were much lower. Linear fits of de-trended $I$ and $Q$ versus temperature showed no significant correlation supporting minimal temperature effect in late spring. The standard deviations of $I$ and $Q$ were well below the 50 and $650 \mathrm{ppm}$ threshold and all data were of good quality. Multiple years of field experience with the EM31 instrument in late spring conditions and the poor linear fits of $I$ and $Q$ versus air temperature gave confidence that the temperature effect was not significant at the WSN. 
https://doi.org/10.5194/tc-2021-61

Preprint. Discussion started: 17 May 2021

(c) Author(s) 2021. CC BY 4.0 License.

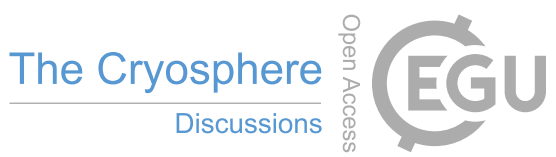

\section{(c) (1)}
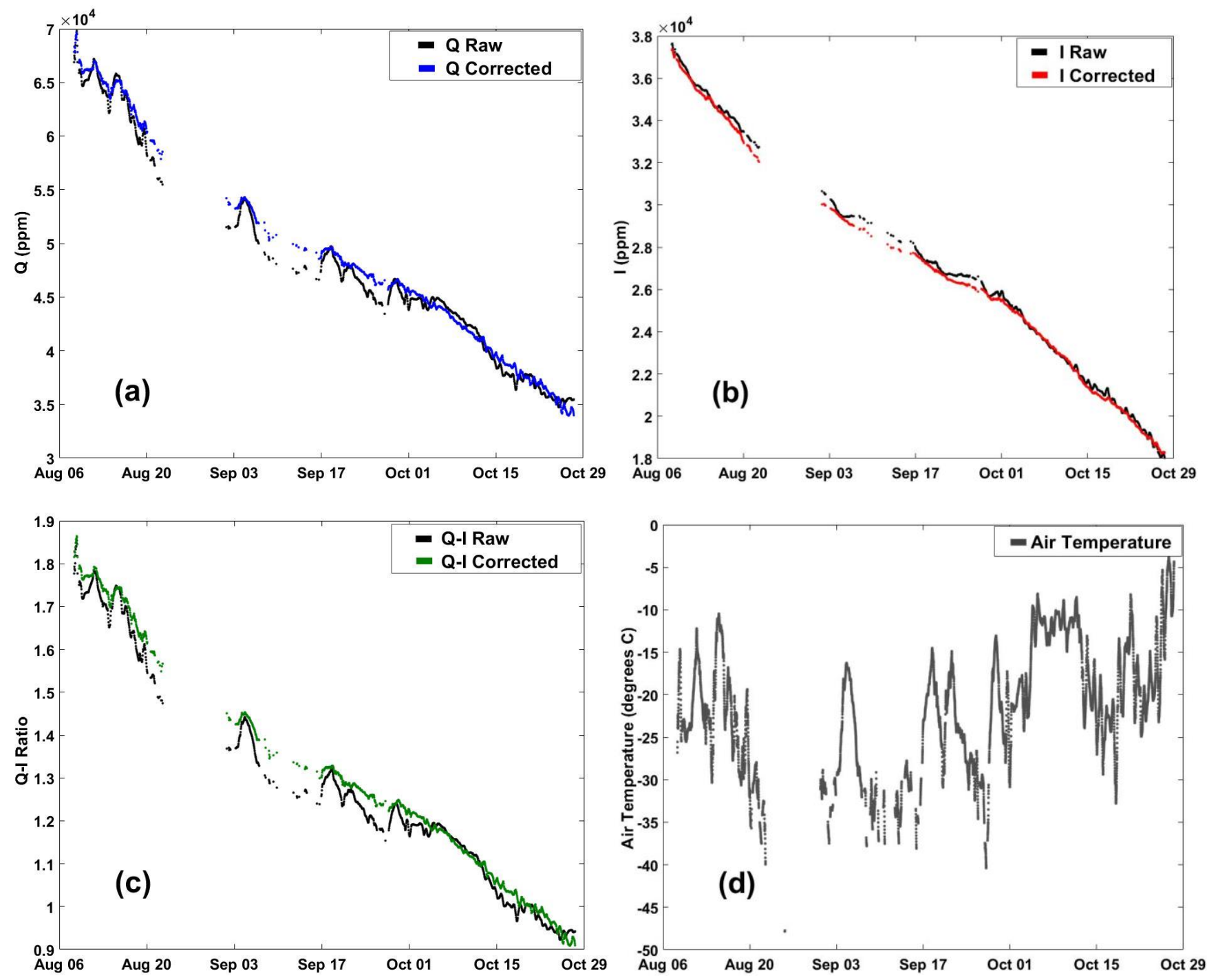

590 Figure A1. SIMBS EM time-series of temperature-corrected (a) $Q$ (blue), (b) $I$ (red), and (c) $Q$ to $I$ ratios (green) with their respective raw uncorrected (black) values, and (d) air temperature (grey) measured by the Campbell Scientific CR3000 data-logger at the site. 
https://doi.org/10.5194/tc-2021-61

Preprint. Discussion started: 17 May 2021

(c) Author(s) 2021. CC BY 4.0 License.

(c)
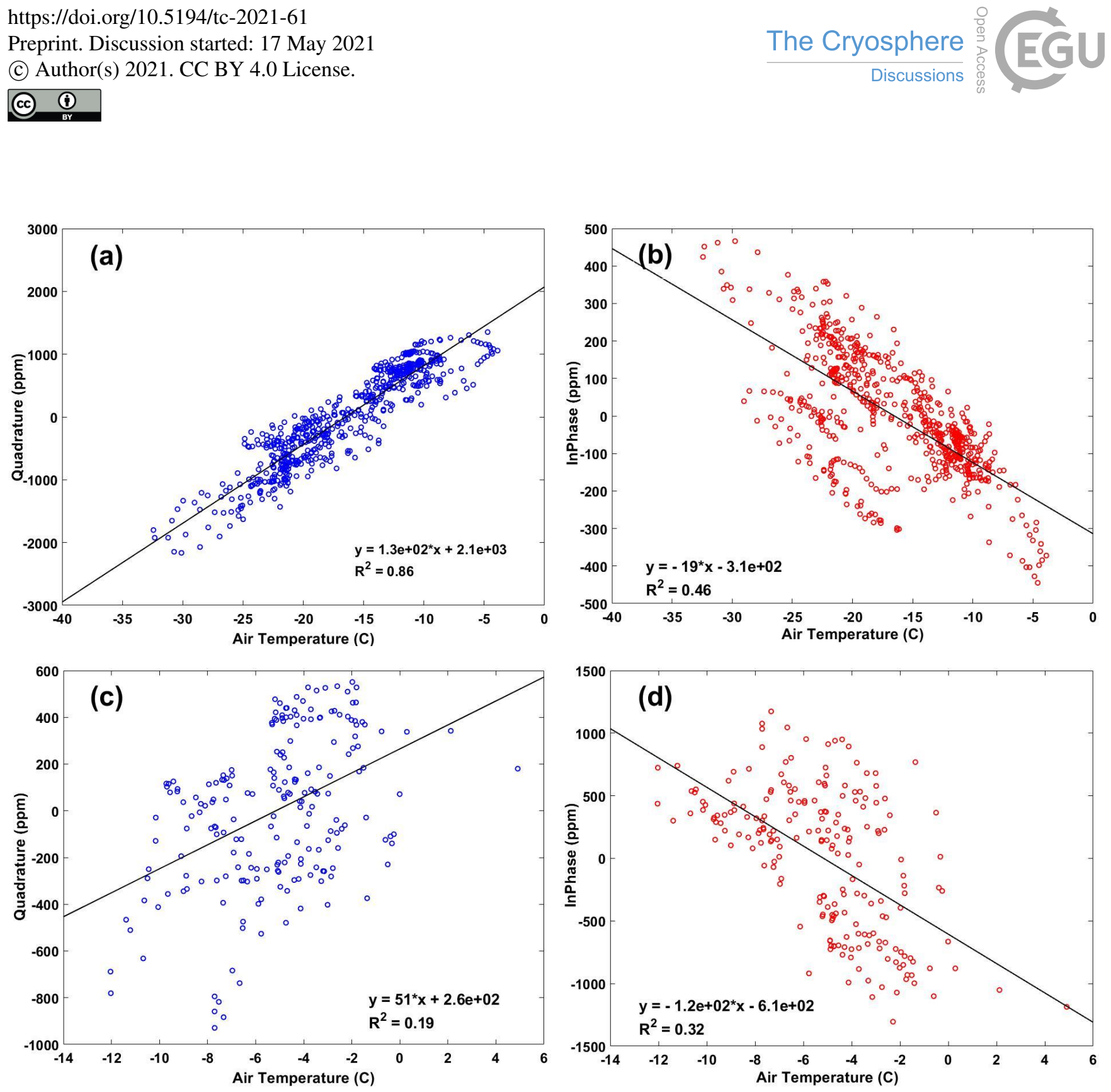

595 Figure A2. Average hourly $Q(($ a) and (c)) and $I((\mathbf{b})$ and (d)) de-trended for the approximately linear growth signal plotted against air temperature measured by the data-logger over winter at the SIMBS ((a) and (b)) and in late spring at the WSN ((c) and (d)) with linear fits applied. The equations of the line and $\mathbf{R}^{2}$ values are given.

Data availability. The 2011, 2013, 2016 and 2017 west-east transects shown in Figure 3 from Brett et al. (2020b) were obtained at PANGAEA (https://doi.org/10.1029/2019JC015678). The data will be made available at the World Data Center PANGAEA https://www.pangaea.de.

Author contributions. GB, GL and WR modified the EM31 instrument for the winter deployment. GB designed the late spring field work and GB and GL collected the field data in November 2018. GB carried out the data processing, analyses and 
https://doi.org/10.5194/tc-2021-61

Preprint. Discussion started: 17 May 2021

(c) Author(s) 2021. CC BY 4.0 License.

(c) (i)

interpretation, and wrote the manuscript with input from all co-authors. AI developed the EM forward model and inversion technique in collaboration with $\mathrm{CH}$. WR, $\mathrm{CH}, \mathrm{PL}$ and $\mathrm{AI}$ contributed to the development of the methodology and manuscript.

Competing interests. The authors declare that they have no conflict of interest.

610 Acknowledgments, Samples, and Data sources. This research was funded by the Deep South National Science Challenge (Targeted observations and process-informed modeling of Antarctic sea ice), a University of Canterbury Doctoral Scholarship, and logistics support provided by Antarctica New Zealand under K063 (2011, 2013, and 2018) and K066 (2016, 2017 and 2018) events. The research was carried out in New Zealand at Gateway Antarctica, University of Canterbury and the University of Otago. We express our deepest gratitude for the invaluable support provided by Scott Base staff and all K063 and K066 field

615 event members, in particular to Inga Smith, Natalie Robinson, Brett Grant, Pete de Joux and Florence Isaacs. We greatly appreciate the hard efforts of Scott Base winter personnel Sanil Lad and Sam Bamford, and to Nick Key and Geoff Graham from the University of Canterbury for their excellent technical support. We acknowledge the use of imagery from the NASA Worldview application (https://worldview.earthdata.nasa.gov/) operated by the NASA/Goddard Space Flight Center Earth Science Data and Information System (EOSDIS) project. Scott Base Electronic Weather Station data were obtained from CliFlo: NIWA's National 620 Climate Database on the Web at (http://cliflo.niwa.co.nz) retrieved on the 26 August 2019.

\section{References}

Arndt, S., Hoppmann, M., Schmithüsen, H., Fraser, A. D., and Nicolaus, M.: Seasonal and interannual variability of landfast sea ice in Atka Bay, Weddell Sea, Antarctica, The Cryosphere, 14, 2775-2793, 10.5194/tc-14-2775-2020, 2020.

625 Assmann, K., Hellmer, H., and Beckmann, A.: Seasonal variation in circulation and water mass distribution on the Ross Sea continental shelf, Antarctic Science, 15, 3-11, 2003.

Barry, J. and Dayton, P.: Current patterns in McMurdo Sound, Antarctica and their relationship to local biotic communities, Polar Biology, 8, 367-376, 1988.

Brett, G. M., Price, D., Rack, W., and Langhorne, P. J.: Satellite altimetry detection of ice shelf-influenced fast ice, The Cryosphere

630 Discuss., 2020, 1-20, 10.5194/tc-2020-286, 2020a.

Brett, G. M., Irvin, A., Rack, W., Haas, C., Langhorne, P. J., and Leonard, G. H.: Variability in the Distribution of Fast Ice and the Sub-ice Platelet Layer Near McMurdo Ice Shelf, Journal of Geophysical Research: Oceans, 125, e2019JC015678, https://doi.org/10.1029/2019JC015678, 2020b.

Dempsey, D. E., Langhorne, P. J., Robinson, N. J., Williams, M. J. M., Haskell, T. G., and Frew, R. D.: Observation and modeling of

635 platelet ice fabric in McMurdo Sound, Antarctica, Journal of Geophysical Research, 115, 10.1029/2008jc005264, 2010.

Egbert, G. D. and Erofeeva, S. Y.: Efficient inverse modeling of barotropic ocean tides, Journal of Atmospheric and Oceanic Technology, 19, 183-204, 2002.

Foldvik, A. and Kvinge, T.: Conditional instability of sea water at the freezing point, Deep Sea Research and Oceanographic Abstracts, $169-174$,

640 Frazer, E. K., Langhorne, P. J., Leonard, G. H., Robinson, N. J., and Schumayer, D.: Observations of the Size Distribution of Frazil Ice in an Ice Shelf Water Plume, Geophysical Research Letters, 47, e2020GL090498, https://doi.org/10.1029/2020GL090498, 2020.

Goring, D. G. and Pyne, A.: Observations of sea-level variability in Ross Sea, Antarctica, New Zealand Journal of Marine and Freshwater Research, 37, 241-249, 2003.

Gough, A. J., Mahoney, A. R., Langhorne, P. J., Williams, M. J., Robinson, N. J., and Haskell, T. G.: Signatures of supercooling:

645 McMurdo Sound platelet ice, Journal of Glaciology, 58, 38-50, 2012.

Haas, C.: Comparison of sea-ice thickness measurements under summer and winter conditions in the Arctic using a small electromagnetic induction device, Geophysics, 62, 749, 10.1190/1.1444184, 1997. 
https://doi.org/10.5194/tc-2021-61

Preprint. Discussion started: 17 May 2021

(c) Author(s) 2021. CC BY 4.0 License.
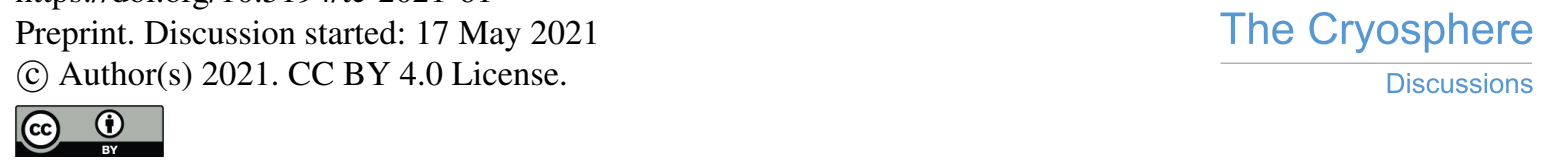

Haas, C., Lobach, J., Hendricks, S., Rabenstein, L., and Pfaffling, A.: Helicopter-borne measurements of sea ice thickness, using a small and lightweight, digital EM system, Journal of Applied Geophysics, 67, 234-241, 10.1016/j.jappgeo.2008.05.005, 2009.

650 Haas, C., Langhorne, P. J., Rack, W., Leonard, G. H., Brett, G. M., Price, D., Beckers, J. F., and Gough, A. J.: Airborne mapping of the sub-ice platelet layer under fast ice in McMurdo Sound, Antarctica, The Cryosphere Discuss., 2020, 1-31, 10.5194/tc-2020-268, 2020.

Haas, C., Langhorne, P. J., Rack, W., Leonard, G. H., Brett, G. M., Price, D., Beckers, J. F., and Gough, A. J.: Airborne mapping of the sub-ice platelet layer under fast ice in McMurdo Sound, Antarctica, The Cryosphere, 15, 247-264, 10.5194/tc-15-247-2021, 2021.

Holland, P. R. and Feltham, D. L.: Frazil dynamics and precipitation in a water column with depth-dependent supercooling, Journal of

655 Fluid Mechanics, 530, 101-124, 2005.

Hoppmann, M., Nicolaus, M., Hunkeler, P. A., Heil, P., Behrens, L. K., König-Langlo, G., and Gerdes, R.: Seasonal evolution of an iceshelf influenced fast-ice regime, derived from an autonomous thermistor chain, Journal of Geophysical Research: Oceans, 120, 1703-1724, 10.1002/2014jc010327, 2015a.

Hoppmann, M., Richter, M. E., Smith, I. J., Jendersie, S., Langhorne, P. J., Thomas, D. N., and Dieckmann, G. S.: Platelet ice, the

660 Southern Ocean's hidden ice: a review, Annals of Glaciology, 1-28, 2020.

Hoppmann, M., Nicolaus, M., Paul, S., Hunkeler, P. A., Heinemann, G., Willmes, S., Timmermann, R., Boebel, O., Schmidt, T., and Kühnel, M.: Ice platelets below Weddell Sea landfast sea ice, Annals of Glaciology, 56, 175-190, $2015 \mathrm{~b}$.

Hughes, K., Langhorne, P., Leonard, G., and Stevens, C.: Extension of an Ice Shelf Water plume model beneath sea ice with application in McMurdo Sound, Antarctica, Journal of Geophysical Research: Oceans, 119, 8662-8687, 2014.

665 Hunkeler, P. A., Hendricks, S., Hoppmann, M., Paul, S., and Gerdes, R.: Towards an estimation of sub-sea-ice platelet-layer volume with multi-frequency electromagnetic induction sounding, Annals of Glaciology, 56, 137-146, 10.3189/2015AoG69A705, 2015.

Hunkeler, P. A., Hoppmann, M., Hendricks, S., Kalscheuer, T., and Gerdes, R.: A glimpse beneath Antarctic sea ice: Platelet layer volume from multifrequency electromagnetic induction sounding, Geophysical Research Letters, 43, 222-231,

https://doi.org/10.1002/2015GL065074, 2016.

670 Hunt, B. M., Hoefling, K., and Cheng, C.-H. C.: Annual warming episodes in seawater temperatures in McMurdo Sound in relationship to endogenous ice in notothenioid fish, Antarctic Science, 15, 333-338, 2003.

Irvin, A.: Towards Multi-Channel Inversion of Electromagnetic Sea Ice Surveys, Published doctoral thesis, York University, Toronto, Canada, http://hdl.handle.net/10315/35925, 2018.

Jacobs, S., Helmer, H., Doake, C., Jenkins, A., and Frolich, R.: Melting of ice shelves and the mass balance of Antarctica, Journal of

675 Glaciology, 38, 375-387, 1992.

Jacobs, S. S., Fairbanks, R. G., and Horibe, Y.: Origin and evolution of water masses near the Antarctic continental margin: Evidence from $\mathrm{H} 218 \mathrm{O} / \mathrm{H} 216 \mathrm{O}$ ratios in seawater, Oceanology of the Antarctic continental shelf, 43, 59-85, 1985.

Jenkins, A. and Bombosch, A.: Modeling the effects of frazil ice crystals on the dynamics and thermodynamics of ice shelf water plumes, Journal of Geophysical Research: Oceans, 100, 6967-6981, 1995.

680 Jordan, J. R., Kimura, S., Holland, P. R., Jenkins, A., and Piggott, M. D.: On the conditional frazil ice instability in seawater, Journal of Physical Oceanography, 45, 1121-1138, 2015.

Langhorne, P. J., Hughes, K. G., Gough, A. J., Smith, I. J., Williams, M. J. M., Robinson, N. J., Stevens, C. L., Rack, W., Price, D., Leonard, G. H., Mahoney, A. R., Haas, C., and Haskell, T. G.: Observed platelet ice distributions in Antarctic sea ice: An index for oceanice shelf heat flux, Geophysical Research Letters, 42, 5442-5451, 10.1002/2015g1064508, 2015.

685 Leonard, G. H., Purdie, C. R., Langhorne, P. J., Haskell, T. G., Williams, M. J. M., and Frew, R. D.: Observations of platelet ice growth and oceanographic conditions during the winter of 2003 in McMurdo Sound, Antarctica, Journal of Geophysical Research - Oceans, 111, C04012, 10.1029/2005JC002952, 2006.

Leonard, G. H., Langhorne, P. J., Williams, M. J., Vennell, R., Purdie, C. R., Dempsey, D. E., Haskell, T. G., and Frew, R. D.: Evolution of supercooling under coastal Antarctic sea ice during winter, Antarctic Science, 23, 399-409, 2011.

690 Lewis, E. and Perkin, R.: The winter oceanography of McMurdo Sound, Antarctica, Oceanology of the Antarctic continental shelf, 145$165,1985$.

MacAyeal, D. R.: Thermohaline circulation below the Ross Ice Shelf: A consequence of tidally induced vertical mixing and basal melting, Journal of Geophysical Research: Oceans, 89, 597-606, 1984.

Mahoney, A. R., Gough, A. J., Langhorne, P. J., Robinson, N. J., Stevens, C. L., Williams, M. M., and Haskell, T. G.: The sea sonal

695 appearance of ice shelf water in coastal Antarctica and its effect on sea ice growth, Journal of Geophysical Research: Oceans (1978-2012), $116,2011$.

McDougall, T. J. and Barker, P. M.: Getting started with TEOS-10 and the Gibbs Seawater (GSW) oceanographic toolbox, SCOR/IAPSO WG, 127, 1-28, 2011.

Ohshima, K. I., Nihashi, S., and Iwamoto, K.: Global view of sea-ice production in polynyas and its linkage to dense/bottom water

700 formation, Geoscience Letters, 3, 13, 2016.

Padman, L., Erofeeva, S., and Joughin, I.: Tides of the Ross Sea and Ross Ice Shelf cavity, Antarctic Science, 15, $31,2003$.

Padman, L., Erofeeva, S. Y., and Fricker, H. A.: Improving Antarctic tide models by assimilation of ICESat laser altimetry over ice shelves, Geophysical Research Letters, 35, 2008. 
https://doi.org/10.5194/tc-2021-61

Preprint. Discussion started: 17 May 2021

(c) Author(s) 2021. CC BY 4.0 License.

705 validated ICESat laser altimeter data, Journal of Geophysical Research: Oceans, 118, 3634-3650, 2013.

Price, D., Rack, W., Langhorne, P., Haas, C., Leonard, G., and Barnsdale, K.: The sub-ice platelet layer and its influence on freeboard to thickness conversion of Antarctic sea ice, The Cryosphere, 8, 1031-1039, 2014.

Price, D., Beckers, J., Ricker, R., Kurtz, N., Rack, W., Haas, C., Helm, V., Hendricks, S., Leonard, G., and Langhorn, P.: Evaluation of CryoSat-2 derived sea-ice freeboard over fast ice in McMurdo Sound, Antarctica, Journal of Glaciology, 61, 285-300, 2015.

710 Rack, W., Haas, C., and Langhorne, P. J.: Airborne thickness and freeboard measurements over the McMurdo Ice Shelf, Antarctica, and implications for ice density, Journal of Geophysical Research: Oceans, 118, 5899-5907, 10.1002/2013jc009084, 2013.

Robinson, N., Williams, M., Barrett, P., and Pyne, A.: Observations of flow and ice-ocean interaction beneath the McMurdo Ice Shelf, Antarctica, Journal of Geophysical Research: Oceans (1978-2012), 115, 2010.

Robinson, N. J., Stevens, C. L., and McPhee, M. G.: Observations of amplified roughness from crystal accretion in the sub-ice ocean

715 boundary layer, Geophysical Research Letters, 44, 1814-1822, 10.1002/2016gl071491, 2017.

Robinson, N. J., Williams, M. J. M., Stevens, C. L., Langhorne, P. J., and Haskell, T. G.: Evolution of a supercooled Ice Shelf Water plume with an actively growing subice platelet matrix, Journal of Geophysical Research: Oceans, 119, 3425-3446, 10.1002/2013JC009399, 2014.

Smith, I. J., Langhorne, P. J., Frew, R. D., Vennell, R., and Haskell, T. G.: Sea ice growth rates near ice shelves, Cold Regions Science and

720 Technology, 83-84, 57-70, 10.1016/j.coldregions.2012.06.005, 2012.

Smith, I. J., Langhorne, P. J., Haskell, T. G., Joe Trodahl, H., Frew, R., and Ross Vennell, M.: Platelet ice and the land-fast sea ice of McMurdo Sound, Antarctica, Annals of Glaciology, 33, 21-27, 2001.

Stern, A., Dinniman, M., Zagorodnov, V., Tyler, S., and Holland, D.: Intrusion of warm surface water beneath the McMurdo Ice Shelf, Antarctica, Journal of Geophysical Research: Oceans, 118, 7036-7048, 2013. 